\title{
A new basal ornithopod dinosaur from the Upper Cretaceous of South Korea
}

\author{
Min Huh, Dae-Gil Lee, Jung-Kyun Kim, Gwangju, Jong-Deock Lim, Daejeon, \\ and Pascal Godefroit, Brussels
}

With 18 figures and 2 tables

Huh, M., LeE, D.-G., Kim, J.-K., Lim, J.-D. \& Godefroit, P. (2011): A new basal ornithopod dinosaur from the Upper Cretaceous of South Korea. - N. Jb. Geol. Paläont. Abh., 259: 1-24; Stuttgart.

\begin{abstract}
The Seonso Conglomerate (?Santonian - Campanian, Late Cretacous) of Boseong site 5 (southern coast of Korean Peninsula) has yielded well-preserved postcranial material belonging to a new taxon of ornithischian dinosaur, Koreanosaurus boseongensis nov. gen., nov. sp. This dinosaur is characterized by elongated neck vertebrae, very long and massive scapulocoracoid and humerus, proportionally short hindlimbs with a low hindlimb ratio for tibia/femur, and anteroposteriorly-elongated femoral head forming an obtuse $135^{\circ}$ angle with the femoral shaft. Koreanosaurus displays a series of neornithischian synapomorphies. Amongst Neornithischia, most features of the postcranial skeleton suggest affinities with basal ornithopods and, amongst them, particularly with a small clade formed by three genera from the Cretaceous of Montana: Zephyrosaurus schaffi, Orodromeus makelai, and Oryctodromeus cubicularis. According to the morphological, phylogenetic, sedimentological, and taphonomic data at hand, it is tentatively postulated that Koreanosaurus was a burrowing dinosaur, like Oryctodromeus.
\end{abstract}

Key words: Boseong, Korea, Late Cretaceous, Koreanosaurus boseongensis nov. gen., nov. sp., dinosaurs, basal ornithopods.

\section{Introduction}

Cretaceous nonmarine deposits are well represented in several sedimentary basins along the southern coast of the South Korean Peninsula. Although dinosaur track sites are particularly numerous, diversified, and well preserved in this area (see e.g. LIM et al. 1994; HuH et al. 1997, 2001; PAIK et al. 2001), skeletal remains are very poor and found at only a few sites (see e.g. LeE et al. 1997; PAIK et al. 1998). Dinosaur eggs and clutches were recently discovered in Cretaceous deposits at Boseong (HuH et al. 1999), Sihwa (LEE et al. 2000), and Goseong (YANG 2000). Discovered in 1999, the Boseong locality is particularly spectacular because of the preservation of numerous intact cluches; based on their eggshell structure they are identified as belonging to ornithopod and sauropod dinosaurs, (HuH $\&$ Zelenitsky 2002). Five fossiliferous sites are repertoried in Boseong locality, extending over three kilometres along the coast of Bibongri of BoseongGun (Fig. 1). In 2003, disarticulated bones (a right femur, the proximal part of a left tibia and a caudal vertebra) were discovered in site 3. Systematic excavations in site 5 lead to the discovery of two larger fossiliferous blocks. These blocks contained respectively the anterior and posterior parts of the postcranium of a small dinosaur, preserved in articulation and in three dimensions. The blocks were discovered 2 meters from each other in the same 


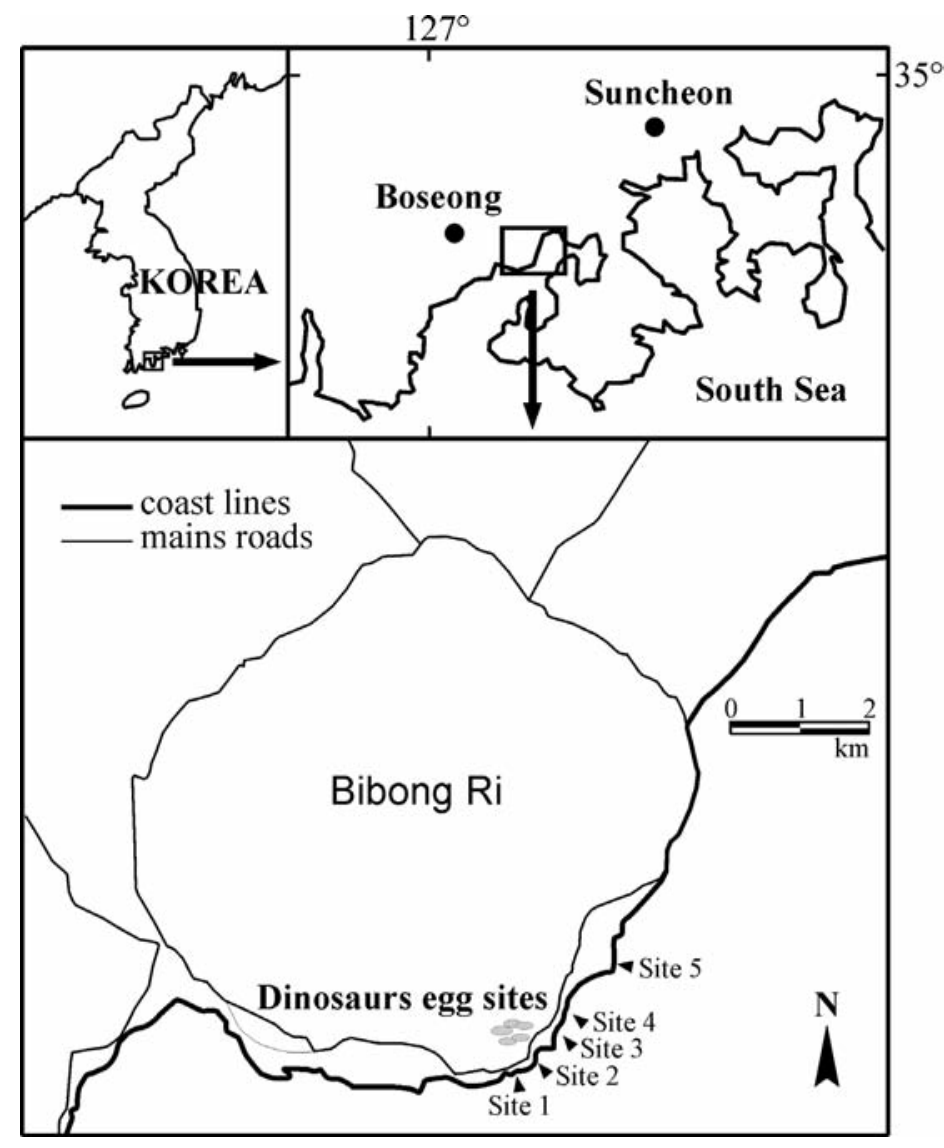

Fig. 1. Location maps of study area.

horizon and at the same level. The two articulated parts contain complementary parts of the skeleton, without overlapping elements, and are preserved in an identical state. Nevertheless, it cannot be definitely proved that the two blocks really belong to the same individual. Here we describe and discuss the dinosaur bones discovered in Boseong locality. These are the most complete dinosaur skeletal remains discovered so far in the Korean Peninsula.

Institutional abbreviations. - IVPP, Institute of Vertebrate Paleontology and Paleoanthropology, Beijing, P.R. China. JLUM, Jilin University Museum, Changchun, P.R. China. KDRC, Korea Dinosaur Research Center, Chonnam National University, Gwangju, Republic of Korea. MOR, Museum of the Rockies, Bozeman, Montana, U.S.A. NHM, Natural History Museum, London, U.K. PMOL, Paleontological Museum of Liaoning, Shenyang, P.R. China.

\section{Geological setting}

The Boseong site is located in a small cauldron basin belonging to a series of transtensional basins formed in South Korea during the Cretaceous (LEE 1999;
Chough et al. 2000). The sedimentary sequences observed at Boseong site consist of epiclastic, pyroclastic, and intermediate to acidic volcanic rocks; they can be divided in ascending order into: (1) the Seonso Conglomerate, (2) the Seonso Formation, (3) the Pilbong Rhyolite, (4) the Mudeungsan Flow, (5) the Obongsan Brecciated Tuff, and (6) the Docheonri Rhyolite (HwANG \& CHEONG 1968). The abundance of volcanic rocks and pyroclastic deposits in sequences of this small isolated basin suggests that they can be time-correlated with the Yucheon Group (Upper Cretaceous) of the Gyeongsang Supergroup in the much larger Gyeongsang Basin, in which volcanic activity was common (KANG et al. 1995). Recent isotope datings at Boseong locality indicate that the fossiliferous sediments are Santonian to Campanian in age (HuH et al. 2006; KIM et al. 2008). Both the dinosaur bones and eggs are included at the base of the sequence in the primarily clastic Seonso Conglomerate. This formation consists of conglomerates, greenish grey to variegated sandy sandstones, and purple mudstones (Fig. 2). The dinosaur bones are included in purple mudstones, interpreted as 


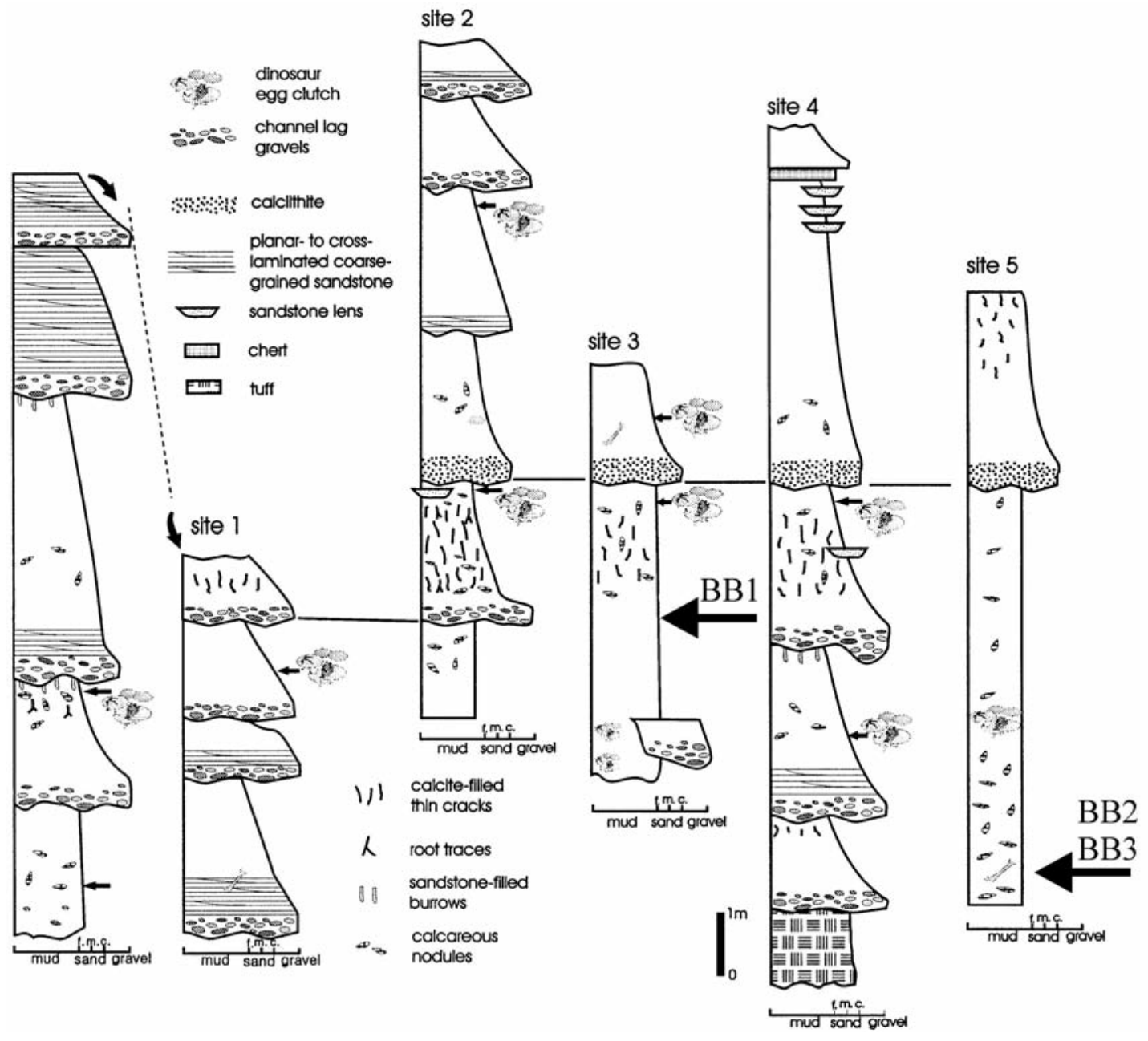

Fig. 2. Stratigraphic sections of Boseong dinosaur locality (from PAIK et al. 2004) and location of the Koreanosaurus boseongensis nov. gen., nov. sp. specimens (KDRC-BB1, BB2, BB3) discovered in this site.

terminal fan deposits (PAIK et al. 2004). The mudstones that host the dinosaur eggs and bones show a variety of pedogenic features. Calcite rims and calcite aureols around detrital grains, pedotubular to nodular calcretes, and circumgranular to circumnodular cracks suggest a calcareous pedogenesis. Vertic features, including pedogenetic slickenslides, pseudoanticlines, and calcite-filled deep desiccation cracks, were also observed. Bioturbation in the fossiliferous mudstones is evidenced in the form of small burrows, with a diameter of about $1 \mathrm{~cm}$ and lengths of a few $\mathrm{cm}$, perpendicular to subperpendicular to the bedding planes and filled with sandstone. The preservation of the dinosaur fossils in calcic and vertic palaeosols suggests that the palaeoclimate was semiarid and seasonal with regard of water availability (PAIK et al. 2004).

\section{Systematic palaeontology}

Dinosauria Owen, 1842

Ornithischia SEELEY, 1887

Neornithischia CoOPER, 1985 (sensu Sereno 1998)

Ornithopoda MARsh, 1881 (sensu ButLer et al. 2008)

Koreanosaurus nov. gen.

Type species: Koreanosaurus boseongensis nov. gen., nov. sp., monotypic.

Etymology: 'Korean lizard'. This is the first relatively complete dinosaur discovered in Korea.

Diagnosis: See specific diagnosis. 


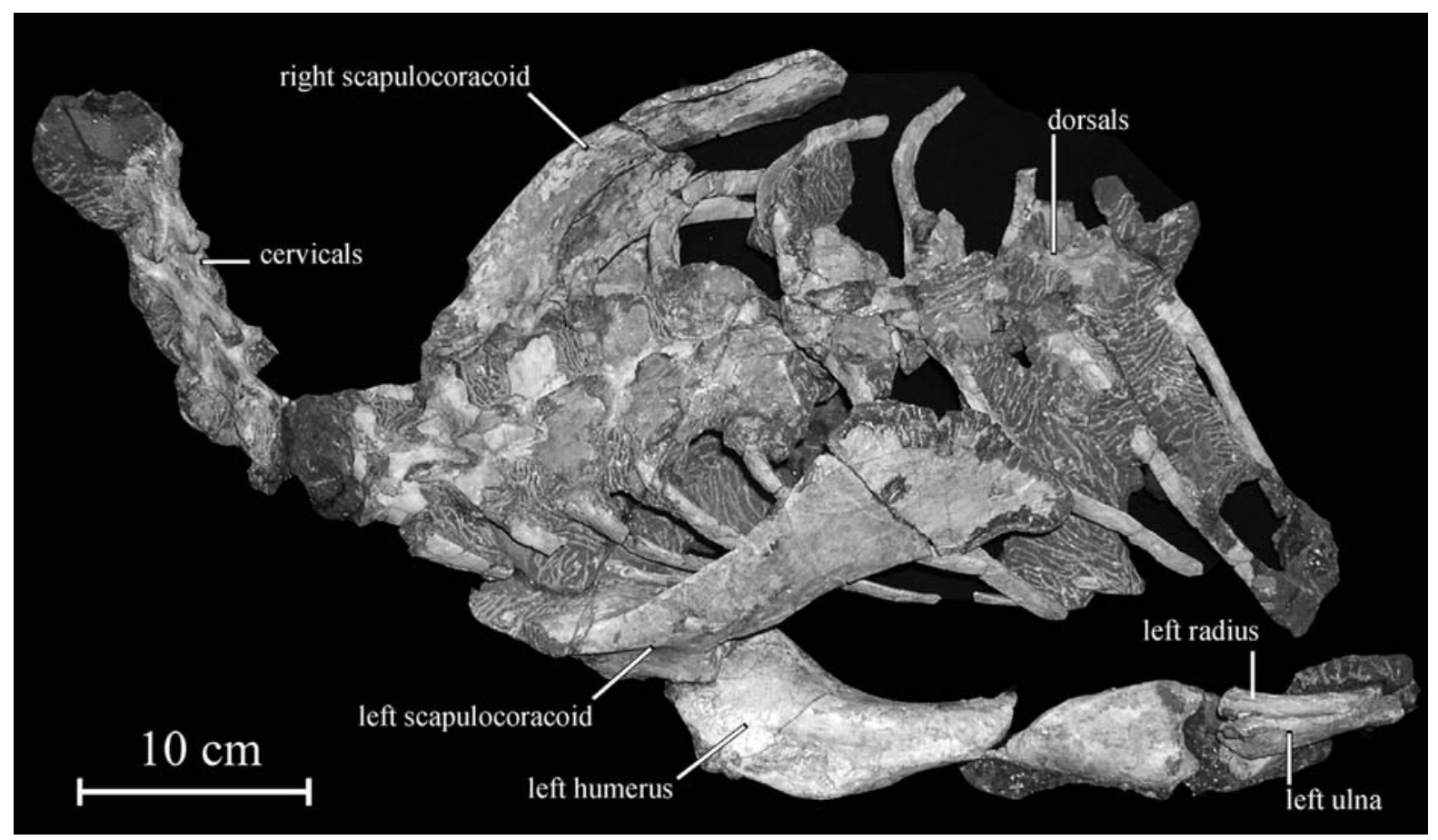

Fig. 3. Holotype of Koreanosaurus boseongensis nov. gen., nov. sp. (KDRC-BB2) in dorsolateral view.

Koreanosaurus boseongensis nov. gen., nov. sp. Figs. 3-17

Etymology: Refers to Boseong County where the holotype and paratype were discovered.

Holotype: KDRC-BB2, including five cervical vertebrae, seven dorsal vertebrae, seventeen dorsal ribs, the nearly complete right and left scapulae, the coracoids, the sternals, the proximal part of the left humerus; the incomplete right humerus, and the proximal part of the left ulna and radius (Fig. 3).

Paratype: KDRC-BB3, including the incomplete sacrum, the partial left ilium and ischium, the complete left femur, tibia and fibula, and the incomplete left tarsus and metatarsus (Fig. 14).

Type 1ocality: Site 5 (Fig. 1), southern coast of Seonso Village, Boseong County, Chollanam-do Province, Republic of Korea.

Type horizon: Seonso Conglomerate (?Santonian Campanian, Late Cretacous; HuH et al. 2006; KIM et al. 2008; Fig. 2).

Referred material: KDRC-BB1, from site 3 in Seonso Village, including an incomplete right femur, the proximal part of a left tibia and one caudal vertebra.
Diagnosis: Basal ornithopod characterized by the following derived characters. Elongated anterior cervicals: ratio 'maximum length from pre-to postzygapophyses/ transverse width across postzygapohyses' about 2.7 for cervicals 4 and 5; blade-like keel on ventral surface of all cervical centra, sharp ventral keel on centra of at least the first seven dorsals (also in Oryctodromeus and Orodromeus); fused scapulocoracoid plate (also in Oryctodromeus); highly-keeled posterior border of proximal ulna (also in Orodromeus); femoral head and shaft forming an obtuse $135^{\circ}$ angle; femoral head anteroposteriorly elongated; low hindlimb ratio of 1.07 for tibia / femur.

Remarks: KDRC-BB2 and 3 were discovered in the same horizon and just 2 meters from each other. These blocks are complementary, there is no overlapping element, and their preservation state is identical. Moreover, the size of posteriormost vertebrae in block BB2 is compatible with the size of the sacrals in block BB3 (Table 1). It can therefore be hypothesised that the two articulated sections belong to the same individual. If it is effectively the case, the following important autapomorphy can be added to the generic and specific diagnosis of Koreanosaurus boseongensis: 'Extreme development of the pectoral girdle and humerus: both the humerus and scapula somewhat longer than the femur'.

The fusion of the scapulocoracoid, the complete fusion (absence of visible sutures) of the centrum and neural ach 


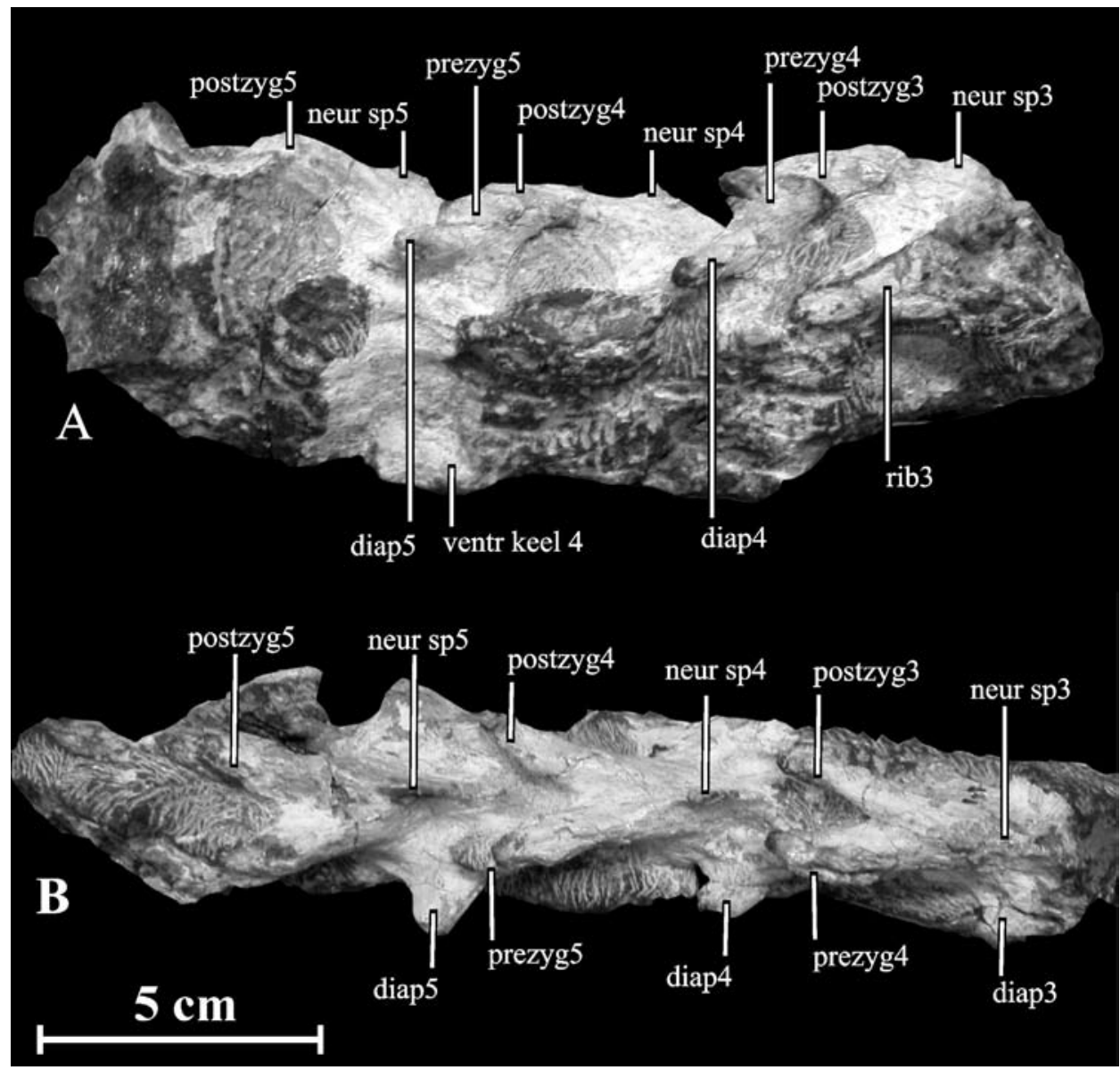

Fig. 4. Cervical vertebrae of Koreanosaurus boseongensis nov. gen., nov. sp. (KDRC-BB2) in right lateral (A) and dorsal (B) views. Diap: diapophysis; neur sp: neural spine; postzyg: postzygapophysis; prezyg: pezygapophysis; rib: cervical rib; ventr keel: ventral keel.

on the cervicals and the dorsals, the fusion (although the sutures remain visible) on the preserved sacral vertebra of the centrum, neural arch and sacral rib, and the possible complete fusion of the astragalus and calcaneum along the distal part of the tibia and fibula suggest that the two articulated series belong to adult individuals. It means that, even if KBRC-BB2 and BB3 belong to different individuals, the great development of the pectoral girdle and humerus relative to the hindlimb can be regarded as a striking character in Koreanosaurus boseongensis.

Table 1. Measurements of the vertebrae of the holotype of Koreanosaurus boseongensis (KDRC-BB2). Cv: cervical vertebra; D: dorsal vertebra; S: sacral vertebra. *taken between the base of the neural spine and the tip of the postzygapophyses.

Cv3: length of postzyagopophyseal process*: $27 \mathrm{~mm}$ width between postzygapophyses: $17 \mathrm{~mm}$
Cv4: length of centrum: $42 \mathrm{~mm}$ height of centrum: $28 \mathrm{~mm}$ length from pre- to postzygapophyses: $57.5 \mathrm{~mm}$ length of postzygapophyseal process $*: 27.6 \mathrm{~mm}$ width between postzygapophyses: $21.5 \mathrm{~mm}$

Cv 5: length of centrum: $42.7 \mathrm{~mm}$ height of centrum: $27.7 \mathrm{~mm}$ length from pre- to postzygapophyses: $57.8 \mathrm{~mm}$ length of postzygapophyseal process $*: 32.4 \mathrm{~mm}$ width between postzygapophyses: $21 \mathrm{~mm}$

D3: length of centrum: $30.5 \mathrm{~mm}$ width of centrum at mid-length: $20.5 \mathrm{~mm}$

D4: length of centrum: $33.7 \mathrm{~mm}$ width of centrum at mid-length: $19.5 \mathrm{~mm}$

D5: length of centrum: $36.5 \mathrm{~mm}$ width of centrum at mid-length $20.5 \mathrm{~mm}$

D6: length of centrum: $36.7 \mathrm{~mm}$ width of centrum at mid-length $20.3 \mathrm{~mm}$

S? 4: width of centrum: $23 \mathrm{~mm}$ Heght of centrum + neural arch: $53 \mathrm{~mm}$ 


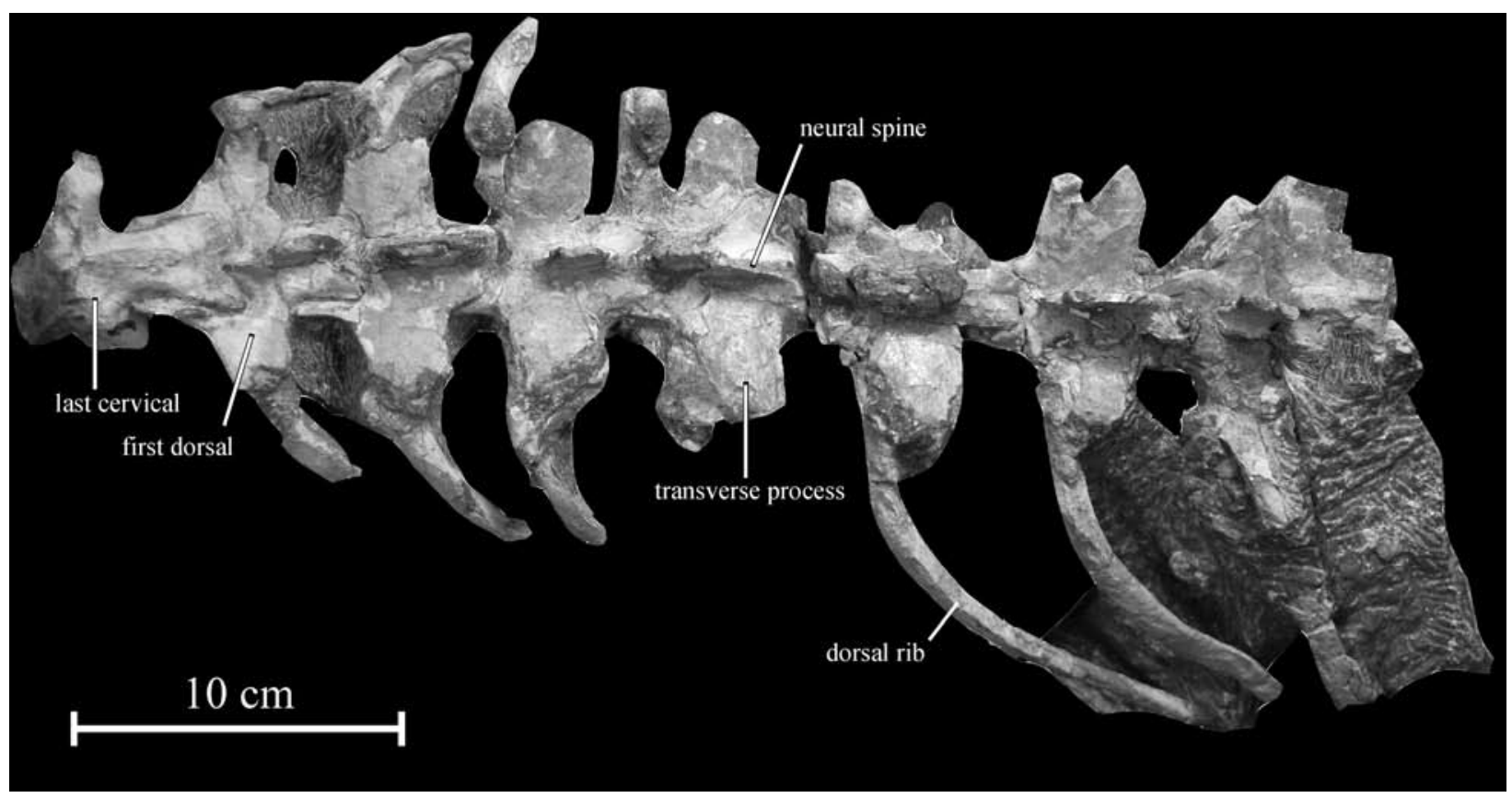

Fig. 5. Dorsal vertebrae of Koreanosaurus boseongensis nov. gen., nov. sp. (KDRC-BB2) in dorsal view.

\section{Description}

Cervical vertebrae. - Four anterior cervical vertebrae are preserved in connection in the holotype, but they are not connected with the trunk part of the specimen (Fig. 4). For facility, they are here referred as cervicals 3 to 6 , but it cannot be excluded that they actually represent cervicals 4 to 7 . A fifth cervical vertebra is preserved in the holotype, in connection with the anterior dorsal series: therefore, it represents the last cervical. All the cervicals are poorly preserved: they are eroded and still incrusted by very hard sediment, therefore precise measurements can only be taken on cervical 3 to 5 (Table 1). The anterior cervicals are strikingly elongated: the centra are approximately 1.5 times as long as high. In Hypsilophodon (pers. obs.) and Orodromeus (SCHEETZ 1999, fig. 16), the centra of the anterior cervicals are only slightly longer than high (length/width ratio around 1.1-1.2). Important elongation of the cervicals was also described, amongst basal ornithopods, in Talenkauen santacrucensis Novas, Cambiaso \& Ambiaso, 2004 and Macrogryphosaurus gondwanicus CALvo, PORFIRI \& Novas, 2007. The articular surfaces of the centra are very poorly exposed, but both ends appear to be slightly concave. In lateral view, the anterior centra are parallelogram-like and inclined posteriorly. As is usual in basal ornithopods, the lateral surfaces of the centra are deeply excavated, being concave both anteroposteriorly and dorsoventrally. There is an elliptical nutrient foramen at mid-length of the centrum, close to the neurocentral suture, as also observed in Changchunsaurus (JLUM L0403-j$\mathrm{Zn} 2$ ). The neurocentral suture is not visible in the cervicals, indicating that the holotype specimen belongs to an adult individual. The ventral margin of the cervical centrum bears a high and thin blade-like keel. A well-developed ventral keel is also developed on the centrum of the cervicals of Orodromeus and Oryctodromeus (VARRICCHIO, pers. comm., October 2009). The ventral crest is much less prominent in other basal ornithopods and ornithischians including Hypsilophodon (Galton 1974, fig.19), Othnielosaurus (GALTON \& JeNSEN 1973; GALTON 2006), Jeholosaurus (IVPP V12529) and Changchunsaurus (JLUM L0403-j-Zn2). The parapophysis forms a distinct process at the anterior end of the centrum, close to or on the neurocentral suture. The diapophyses are much more prominent on the lateral sides of the neural arch. All appear steeply inclined posteriorly. The elongation of the anterior cervicals is particularly striking in dorsal view. The ratio 'maximum length from pre-to postzygapophyses/ 
Fig. 6. Fifth dorsal vertebra in ventral view.

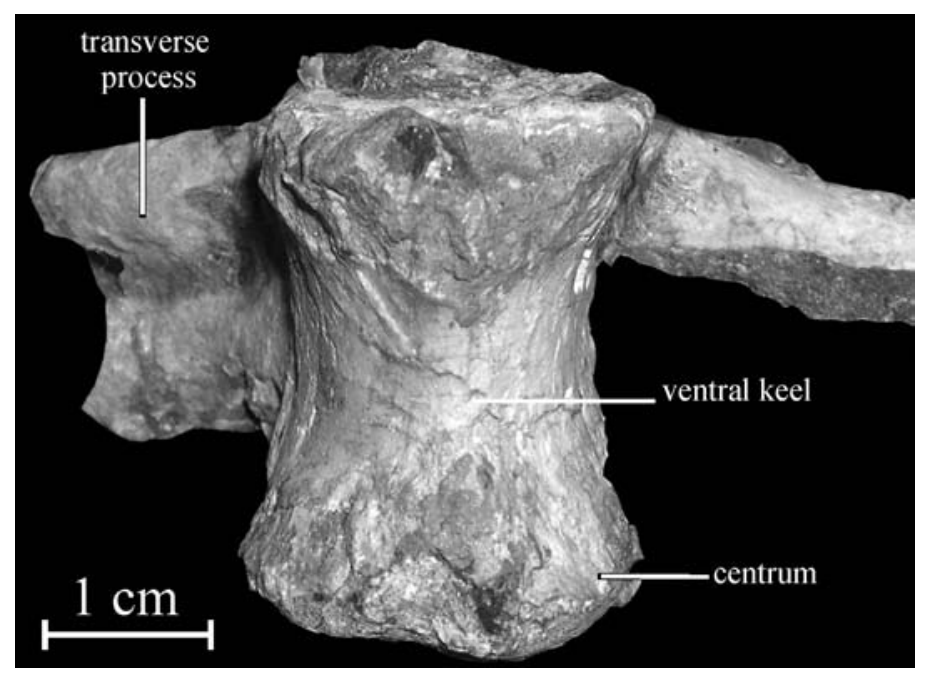

transverse width across postzygapohyses' is respectively 2.67 in the fourth and 2.75 in the fifth cervical. Although it is incomplete, the last cervical appears significantly less elongated than the anterior ones. The prezygapophyses are massive and face medially, dorsally, and slightly anteriorly. Contrary to Talenkauen and Macrogryphosaurus (Novas et al. 2004; CAlvo et al. 2007), epipophyses appear to be absent in Koreanosaurus. In order to compensate for the great elongation of the centrum, the postzygapophyses are very long processes, V-shaped in dorsal view, processes. These postzygapophyseal processes are much more elongated than in other basal ornithopods and ornithischians, including Hypsilophodon (GALton 1974, fig. 20), Orodromeus (ScHEetz 1999, fig. 12), Jeholosaurus (PMOL LPM-R00104) and Changchunsaurus (JLUM L0403-j-Zn2). The postzypapophyseal surfaces face ventrally, laterally, and slightly posteriorly. The neural spines are not well preserved, but they were apparently poorly developed in cervicals 3 to 5 , forming a thin obtuseangled triangular process at the base of the postzygapophyseal processes. The neural spine is much better developed on the anterior cervicals in Jeholosaurus (IVPP V12529) and Changchunsaurus (JLUM L0403-j-Zn2). Although broken off, the
Fig. 7. ?Fourth sacral vertebra of Koreanosaurus boseongensis nov. gen., nov. sp. (KDRC-BB3) in anterior view.

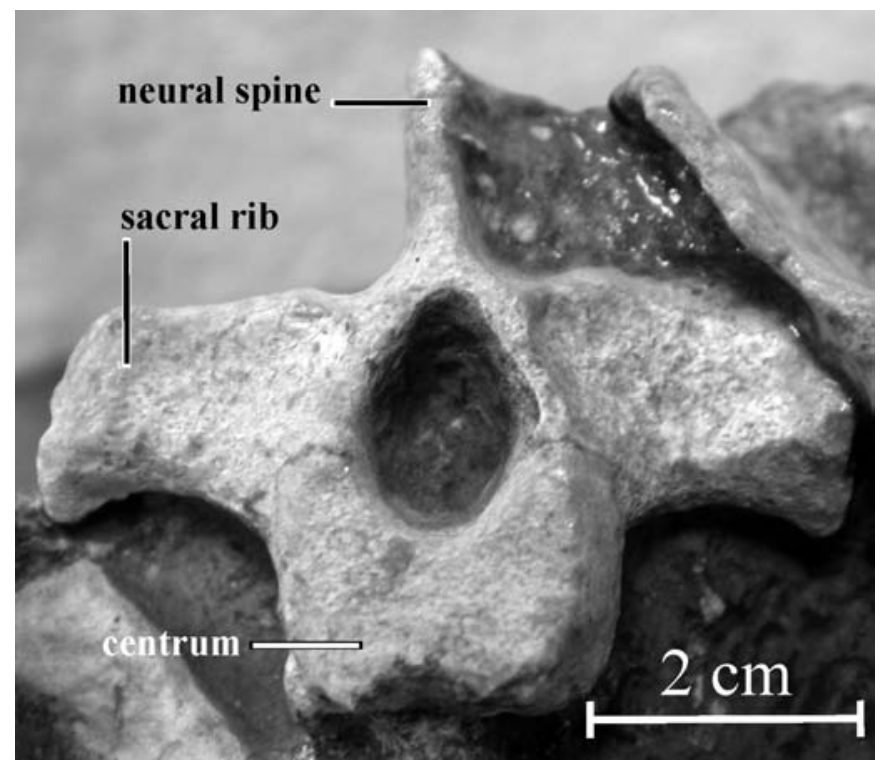




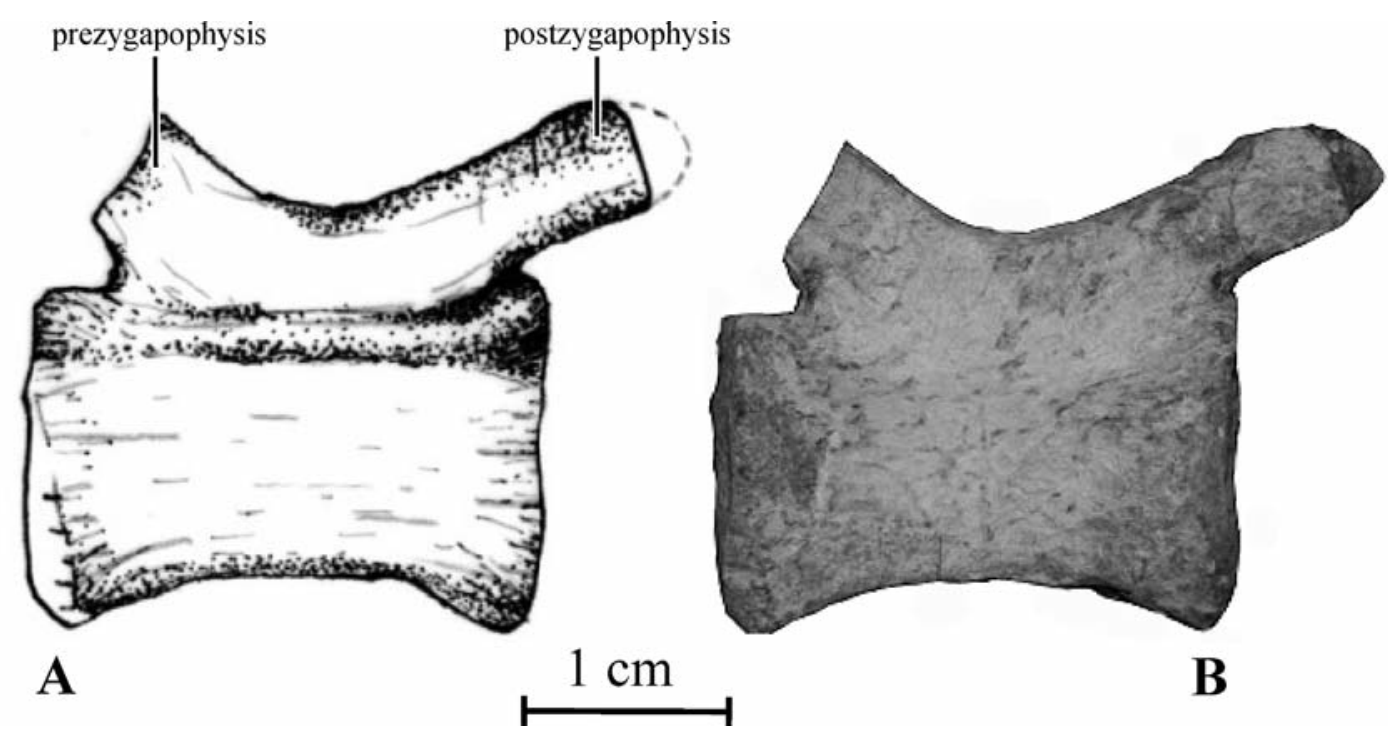

Fig. 8. Interpretative drawing (A) and photograph (B) of a distal caudal vertebra of Koreanosaurus boseongensis nov. gen., nov. sp. (KDRC-BB1) in left lateral view.

neural spine was apparently more extended in the last cervical.

Cervical ribs are partly preserved on the right side of the third cervical and on the left side of the fifth cervical. They appear to be particularly robust and are double-headed, with a short and wide tuberculum and a more slender capitulum.

Dorsal vertebrae. - The first seven dorsal vertebrae of the holotype KDRC-BB2 have been found in connection (Fig. 5). The first dorsal, which is the first presacral vertebra to bear the parapophyses above the neurocentral suture, is still articulated with the last cervical. The dorsals are anteroposteriorly elongated, being about 1.5 times as long as wide (Table 1). This is approximately the same proportion as in Orodromeus (SCHEETZ 1999, fig. 16). The anterior centra are transversely compressed, but they become increasingly spool-like passing along the dorsal series. Although they are poorly exposed, the articular surfaces appear slightly concave. The ventral border of the centrum is regularly concave in lateral view. A well-developed and narrow keel is present on the ventral side of the dorsal centra (Fig. 6). This ventral keel progressively becomes less well developed passing along the dorsal series. A ventral keel is similarly developed on the centrum of the anterior dorsals in Orodromeus and Oryctodromeus (VARRICCHIO, pers. comm., October 2009), and it is in any case better developed than in any other basal ornithischians or ornithopods observed so far, including Hypsilophodon (GALTON 1974, figs. 21-22), Orodromeus (ScHEETz 1999), Hexinlusaurus (HE \& CAI 1984), Jeholosaurus (PMOL LPM-R00104), and Changchunsaurus (JLUM L0403-j-Zn2). There is no trace of a lump-like swelling at the anterior end of the ventral margin of the anterior dorsals, as observed in Changchunsaurus (JLUM L0403-j-Zn2) and Jeholosaurus (BUTLER, pers. comm., April 2009). Small nutritive foramina are sporadically distributed along the lateral surfaces of the centra. The parapophysis progressively migrates dorsally passing along the dorsal series, becoming closer to the diapophysis, but both processes remain separated in the preserved dorsals. The rectangular transverse processes are particularly robust in Koreanosaurus. They are directed laterally and only slightly dorsally. In Oryctodromeus, on the other hand, the transverse processes of the anterior dorsals are steeply angled dorsally (VARricchio et al. 2007, fig. 4a). The pre- and postzygapophyses of the first dorsal are still anteroposteriorly elongated. Although they are mostly poorly preserved, they apparently become less massive passing along the dorsal series. The ventral fossa at the angle between the transverse process and the prezygapophysis is particularly wide and deep in the anterior dorsals. The neural spines are poorly 


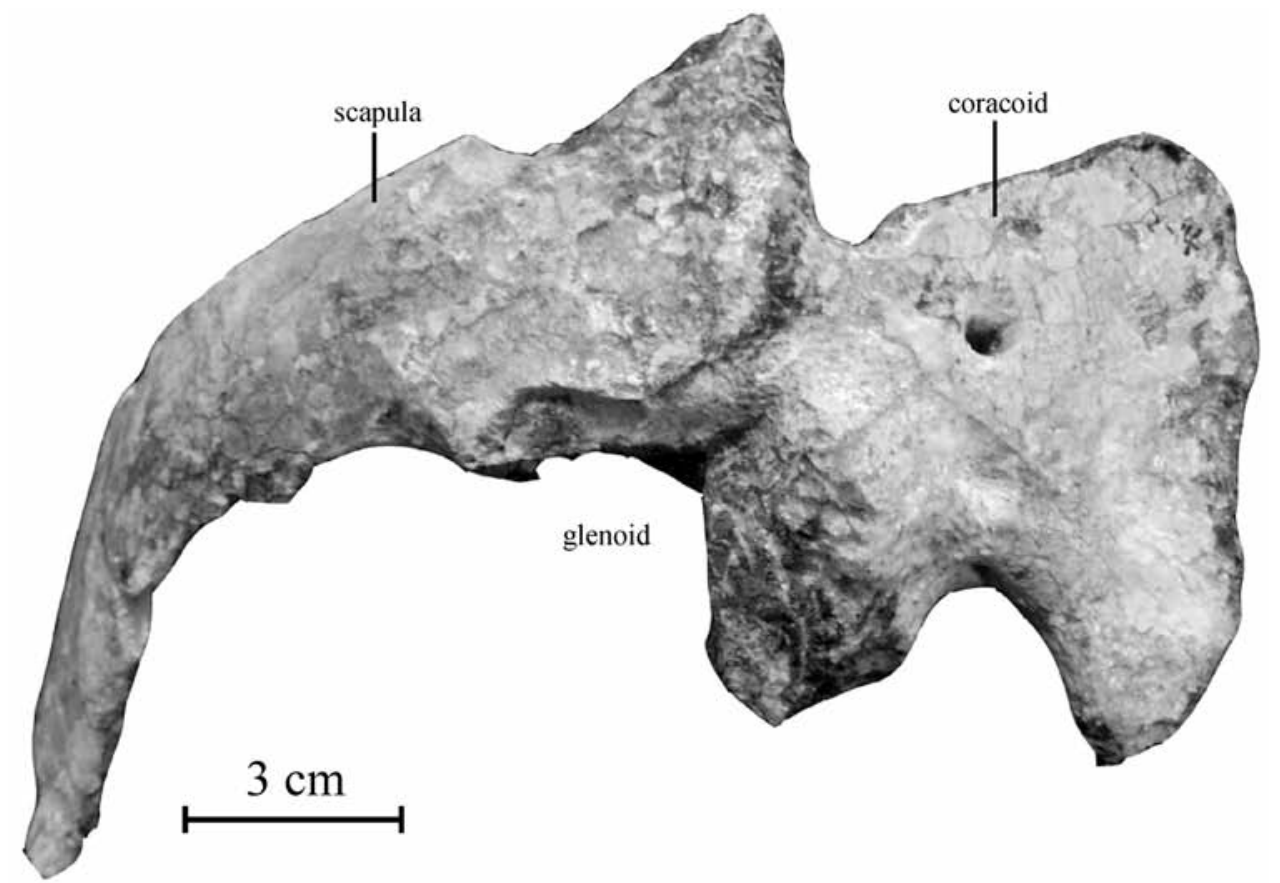

A
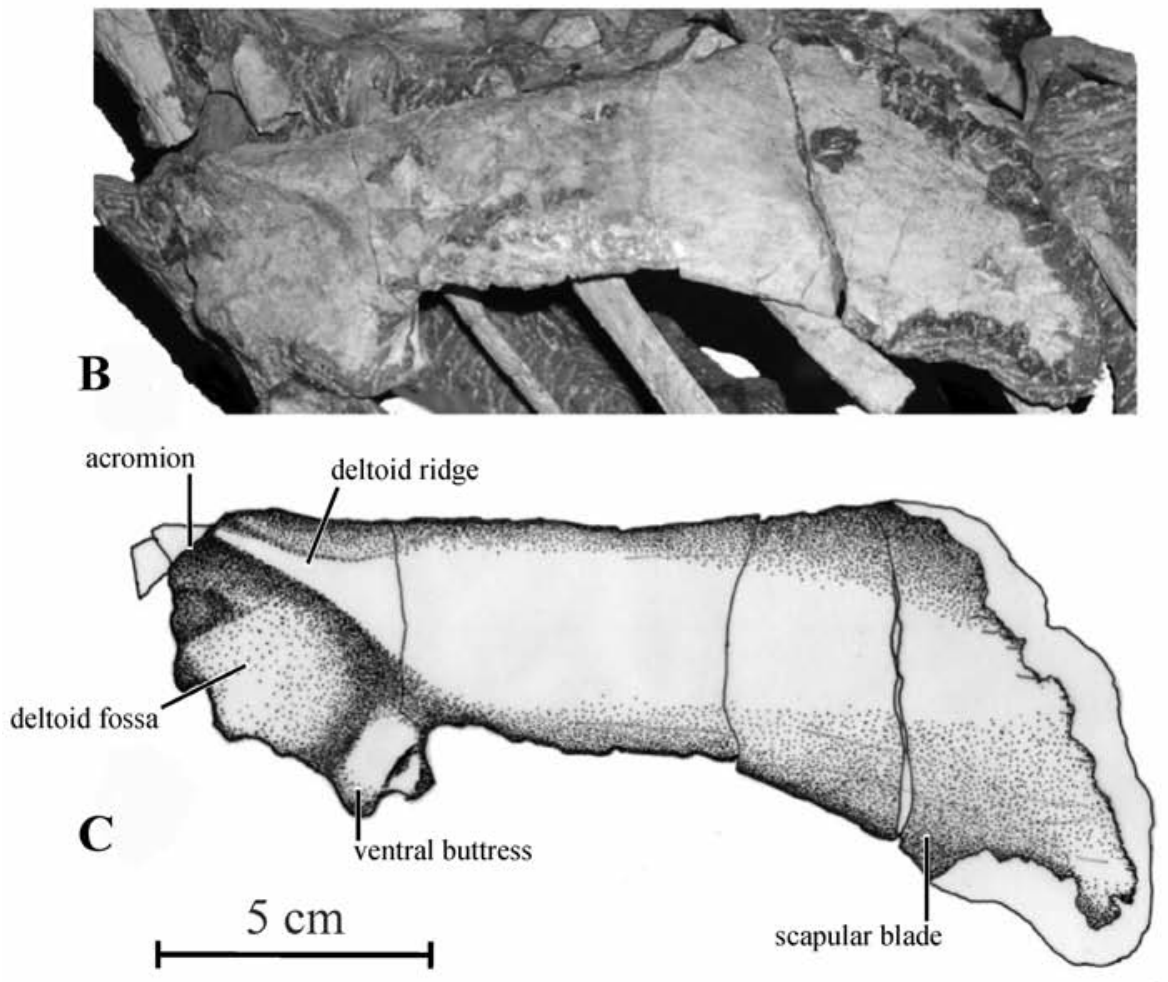

Fig. 9. Koreanosaurus boseongensis nov. gen., nov. sp. Anetrolateral view of the right scapulocoracoid plate (A). Photograph (B) and interpretative drawing (C) of the left scapula of Koreanosaurus boseongensis nov. gen., nov. sp. (KDRC-BB2) in lateral view. 


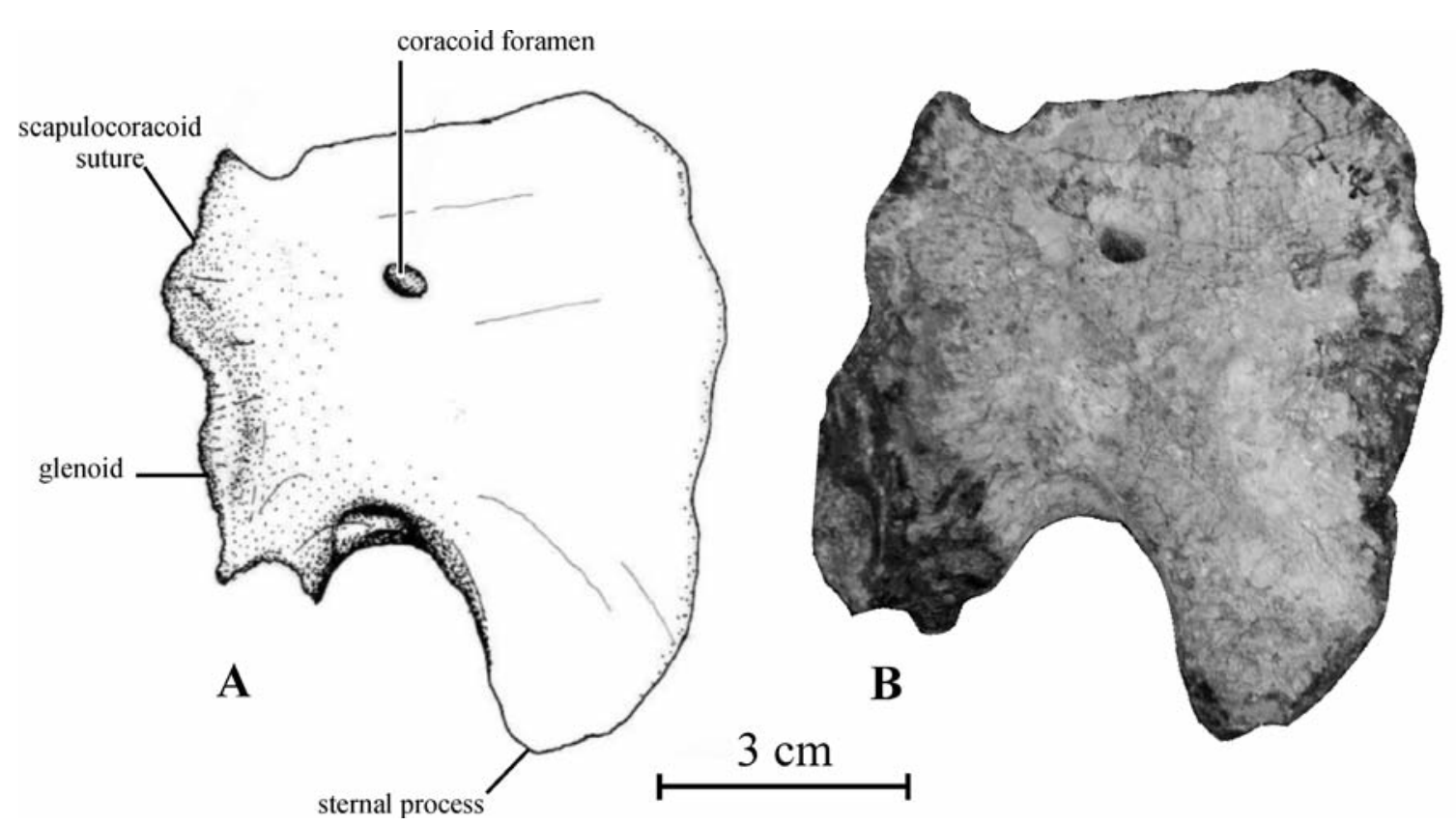

Fig. 10. Interpretative drawing (A) and photograph (B) of the right coracoid of Koreanosaurus boseongensis nov. gen., nov. sp. (KDRC-BB2) in anterolateral view.

preserved. With the possible exception of the first dorsal, they are anteroposteriorly elongated between the pre-and postzygapophyses, relatively low and not inclined posteriorly, closely resembling the dorsal neural spines of Hypsilophodon (GALTON 1974, fig. 22) and Jeholosaurus (PMOL LPM-R00104). In Orodromeus, the neural spine of the anterior dorsals is shorter and inclined posteriorly (SCHEETZ 1999, fig. 14).

Dorsal ribs. - The first eight pairs of dorsal ribs are more or less completely preserved in articulation with the dorsal vertebrae. The longest ribs apparently articulated with the fourth to sixth vertebrae. All the preserved ribs are double-headed. The capitulum is borne on the proximal end of the rib, while the tuberculum is placed more dorsolaterally and faces dorsomedially. On the anterior ribs, the capitulum and the tuberculum are widely separated, but more posteriorly the two heads tend to be closer together. The dorsal ribs are curved, especially near their proximal end. They progressively flatten and widen distally. They are irregularly grooved along their anterior and posterior surfaces. There is no evidence for intercostal processes, as in Hypsilophodon, Parksosaurus, and Thescelosaurus, although this could reflect the subadult status of the individual (ButLer \& GALTON 2008).

S acral vertebrae. - Two sacral vertebrae are partially preserved in KDRC-BB3. One is completely crushed and much eroded, and therefore does not bring any valuable information. The second one is exposed in anterior and right lateral views. It closely resembles the fourth sacral of Hypsilophodon NHM R193 (GALTON 1974: fig. 26a). This sacral is very robust. The centrum is wider than high and its anterior articular surface is flat (Fig. 7). The ventral part of the lateral side of the centrum forms a wide elliptical depressed area. The neural canal is elliptical and higher than wide. The neural spine is anteroposterioly long, low, and transversely wider than in Orodromeus (SCHEETZ 1999). The sacral rib is short but very robust. It is completely fused to the vertebra, but the suture lines are still visible. The greatest part of the rib is borne by the neural arch, but the ventral part of the rib contacts the centrum. The dorsal surface of the rib is thicker than the ventral part and is steeply inclined posterodorsally, as also observed in the fourth sacral rib of Hypsilophodon NHM R196 (GALTON 1974). 


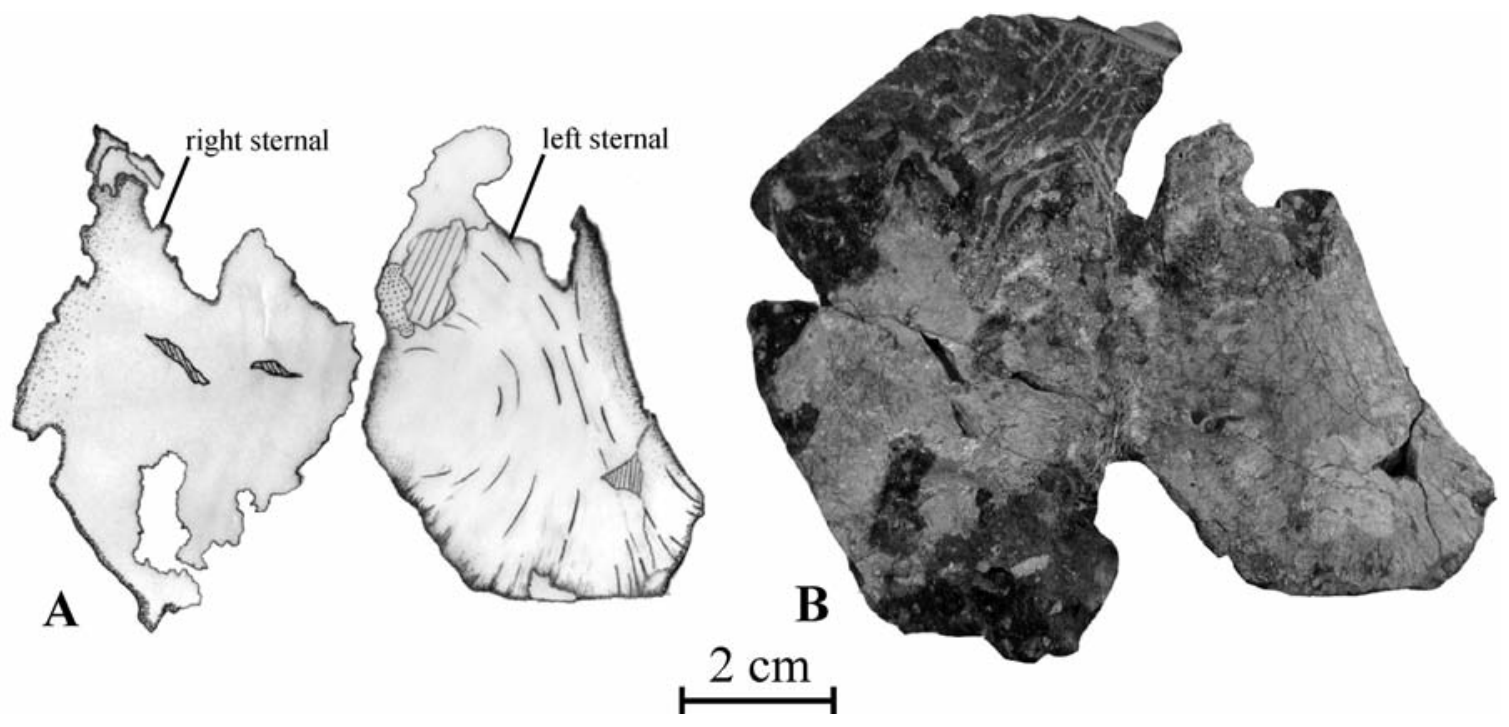

Fig. 11. Interpretative drawing (A) and photograph (B) of the sternal plates of Koreanosaurus boseongensis nov. gen., nov. sp. (KDRC-BB2) in ventral view.

Caudal vertebrae. - One nicely preserved caudal vertebra is associated with the KDRC-BB1 referred material (Fig. 8). This vertebra shows no sign of transverse processes or a neural spine so it belongs to the posterior part of the caudal series. In Hypsilophodon, the transverse processes disappear at the level of the eighteenth caudal and the neural spine at about the thirty-sixth caudal (GALTON 1974). In Thescelosaurus, the transverse processes are absent from the eleventh caudal and the neural spine, from the thirty-sixth caudal (GILMORE 1915). The centrum is amphiplatyan, elongated, and sub-octogonal in cross-section. Small haemapophseal facets are developed on the ventral corners of the anterior articular surface, but they are absent on the posterior articular surface. The neural canal is reduced. The postzygapophyses are long and extend further than the posterior articular surface of the centrum. Their articular facets are oriented quite laterally and they were therefore embraced by the adjacent prezygapophyses from the next caudal vertebra. The prezygapophyses are broken off.

Scapula. - Both the scapula and the coracoid are particularly large and robust. They are fused together, forming an enlarged scapulocoracoid plate, but the respective limits of the bones can still be discerned (Fig. 9A). Amongst basal ornithopods, only Oryctodromeus possesses fused scapulocora- coids (VARRICCHIO et al. 2007, fig. 4c). However, it cannot be excluded that fusion of the scapula and coracoid in basal ornithopod is ontogenetic. The scapula is twisted along its length and regularly bowed medially, so that it follows the outer contour of the rib cage. The proximal plate of the scapula is strongly expanded dorsoventrally (Fig. 9B-C). Its dorsal margin forms a strong deltoid ridge, which limits a vast deltoid fossa on the lateral side of the proximal plate. Although the acromial region of the scapula is destroyed, it was clearly better developed than in Hypsilophodon (GALTON 1974, figs. 34-36), projecting in front of the coracoid and probably forming some kind of scapular spine, like in Zephyrosaurus, Orodromeus (SCHEETZ 1999), and Oryctodromeus (VARRICCHIO et al. 2007). The acromion process is absent in Parksosaurus (PARKs 1926). The ventral sutural surface for the coracoid is transversely thickened. The scapula forms approximately $50 \%$ of the glenoid. Behind the glenoid, the anteroventral angle of the scapula forms a large buttress, which served as attachment site for a powerful $m$. triceps scapularis lateralis externus. The shaft of the scapular blade immediately distal to the proximal plate is also relatively robust: the ratio 'scapula length/minimum height of the blade' is about 5 (6.5-7 in the basal ornithopod Changchunsaurus, for comparison; JLUM L0403-j-Zn2). The ventral margin of the blade is concave in lateral view, 


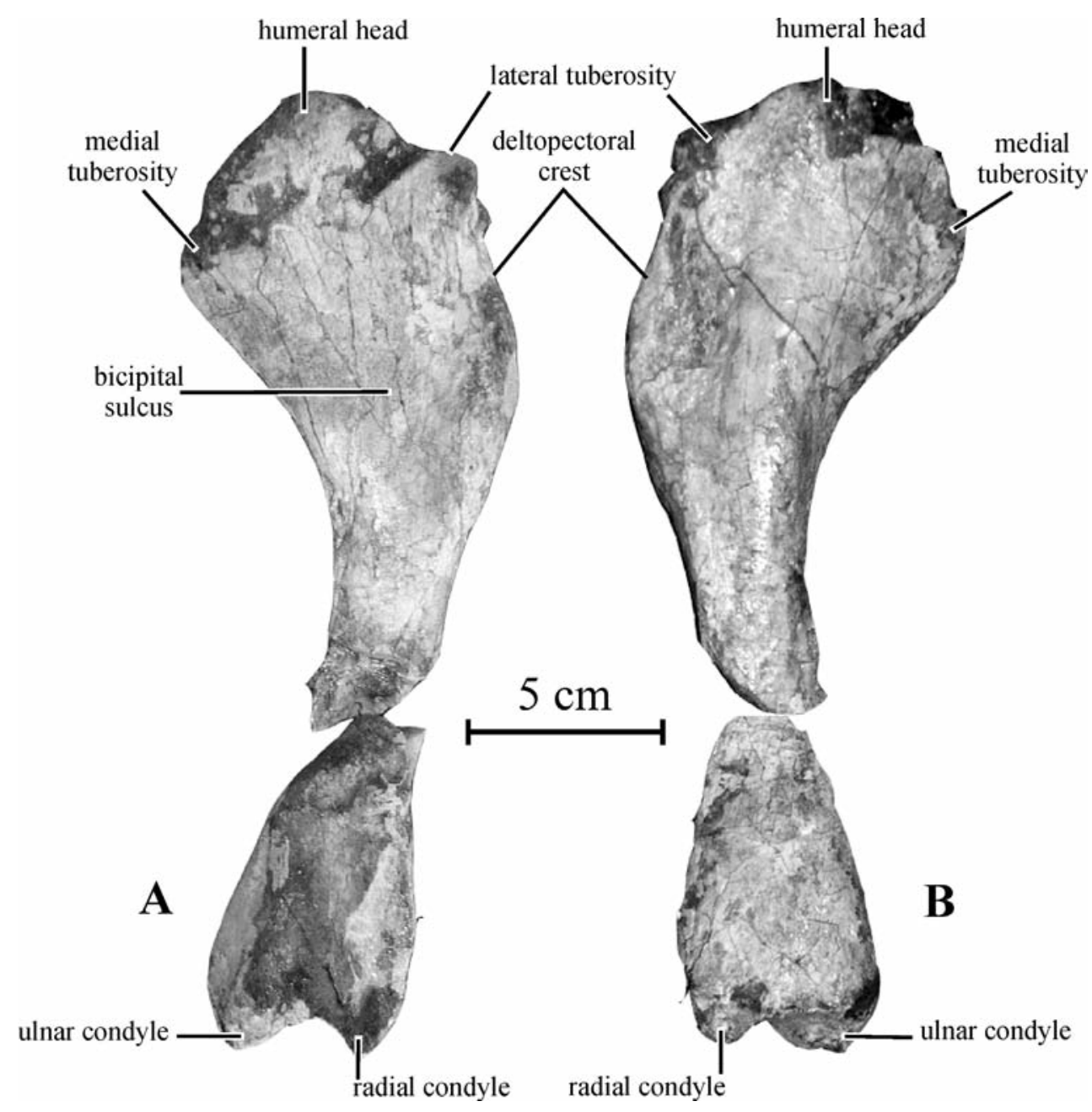

Fig. 12. Left humerus of Koreanosaurus boseongensis nov. gen., nov. sp. (KDRC-BB2) in anterior (A) and posterior (B) views.

whereas its dorsal margin remains nearly straight. As a result, the distal end of the scapular blade is strongly asymmetrically expanded and its maximum height is nearly three times the minimum height of the scapular neck. Such an important and asymmetrical expansion of the distal scapular blade is usually observed in basal ornithopods, including Hypsilophodon (GALton 1974, figs. 34-36), Zephyrosaurus, Orodromeus (SCHEETZ 1999, fig. 19), Jeholosaurus (PMOL LPM-R00104), Changchunsaurus (JLUM L0403-j-Zn2), and Thescelosaurus (GILMORE 1915). A strong ventral bend of the scapular blade is characteristic for Oryctodromeus (VARRICCHIO et al. 2007: fig. 4c).
Coracoid. - The coracoids are also particularly robust in Koreanosaurus. The thin anterior portion is incompletely preserved in both specimens. As preserved, the left coracoid is subrectangular, being approximately $50 \%$ longer than wide (Fig. 10). Both the lateral and medial surfaces are nearly flat. The coracoid is transversely expanded proximally, where it is fused with the scapula. The coracoid part of the posterolaterally-facing glenoid cavity is similar in size and shape to the scapular half of the glenoid. The coracoid foramen perforates the centre of the bone: it is rounded on the lateral surface of the bone and horizontally-elongated elliptical on the medial surface. It is placed more posteriorly in Orodromeus (ScheETZ 1999, fig. 20) and Changchunsaurus 


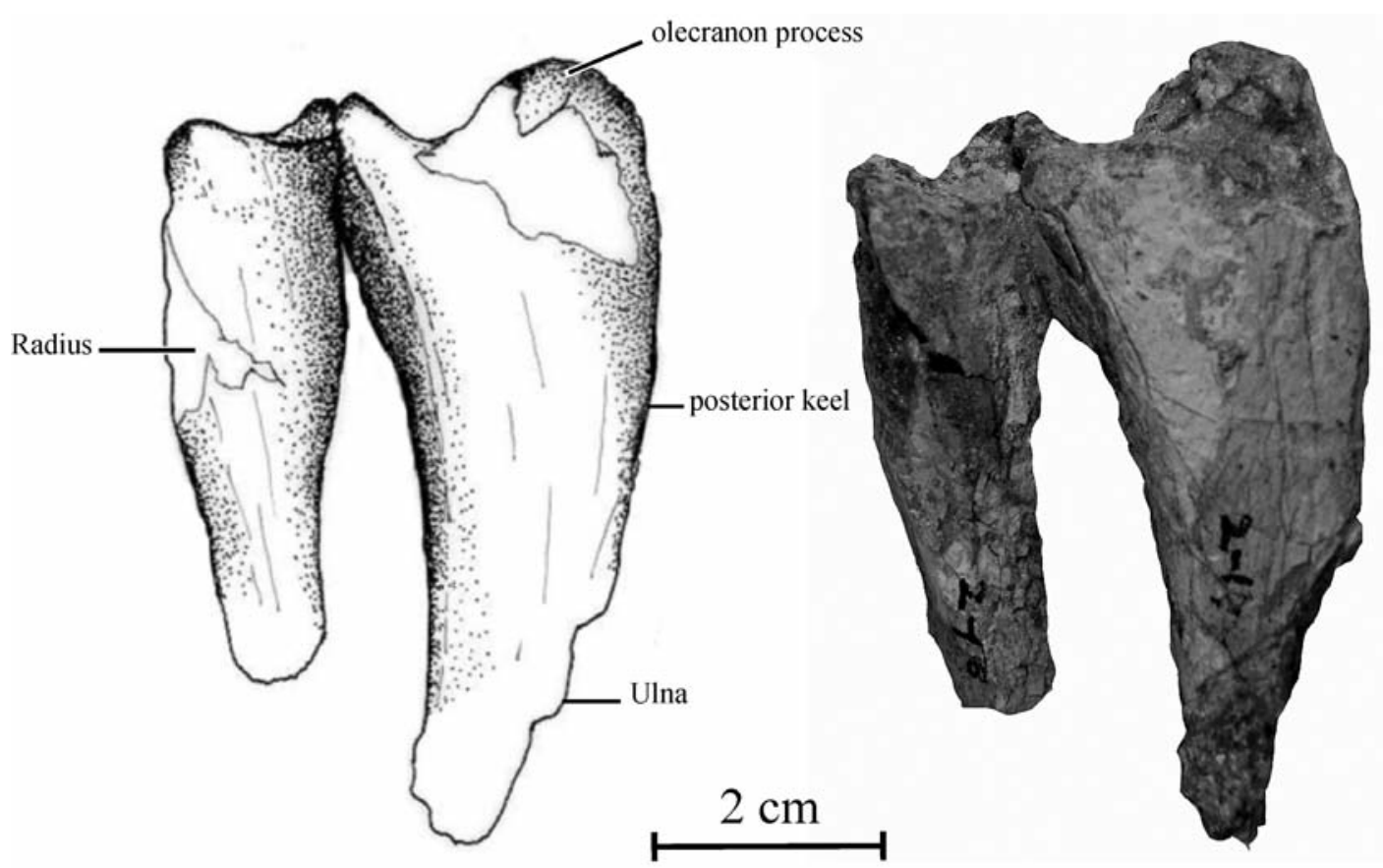

Fig. 13. Interpretative drawing (A) and photograph (B) of the proximal part of the left ulna and radius of Koreanosaurus boseongensis nov. gen., nov. sp. (KDRC-BB2) in lateral view.

(JLUM L0403-j-Zn2). In Hypsilophodon, this foramen is closer to the scapulo-coracoid suture and extends dorsally as a groove that continues onto the scapula (GALTON 1974: fig. 35). The sternal process is particularly prominent on the posteromedial angle of the coracoid in Koreanosaurus and the posterior margin of the bone consequently looks very concave. This process is better developed than in Hypsilophodon (Galton 1974: fig. 35), Orodromeus (SCHEETz 1999, fig. 20), Changchunsaurus (JLUM L0403-j-Zn2), and even Oryctodromeus (VARRICCHIO et al., 2007, fig. 4c).

S tern u m . - Both sternal plates are in connection, immediately behind the sternal process of the cora- coids (Fig. 11). The left sternal is particularly well preserved and is typically kidney-shaped in ventral view, as is usually observed in basal ornithopods including Hypsilophodon (GALTON 1974, fig. 37), Orodromeus (SCHEETZ 1999, fig. 20), and Changchunsaurus (JLUM L0403-j-Zn2). The medial rim is thickened where each element meets its partner. The caudolateral margin is also thickened and roughened, where it probably articulated with the cartilaginous sternal segments of the ribs, as in Hypsilophodon (GALTON 1974, fig. 37B, E). The sternal is distinctly longer than wide in Koreanosaurus, as in other basal ornithopods. Unfortunately, its length cannot be precisely measured, because its anterior portion is destroyed. With a maximal width of $49 \mathrm{~mm}$, the ratio

Table 2. Comparisons of postcranial measurements (in $\mathrm{mm}$ ) in basal ornithopods Koreanosaurus boseongensis, Hypsilophodon foxii, Orodromeus makelai, and Oryctodromeus cubicularis.

\begin{tabular}{lllll}
\hline Taxon & Ref & Humerus length & Femur length & Tibia length \\
\hline K. boseongensis & KDRC-BB & $205-215(\mathrm{BB} 2)$ & $196.5(\mathrm{BB} 3)$ & $204(\mathrm{BB} 3)$ \\
H. foxii & NHM R5829 & 159 & 198 & 238 \\
H.foxii & NHM R5830 & 74 & 101 & 117 \\
O. makelai & MOR 294 & 72 & 106 & 132 \\
O. cubicularis & MOR 1636 & 157 & - & 254 \\
\hline
\end{tabular}




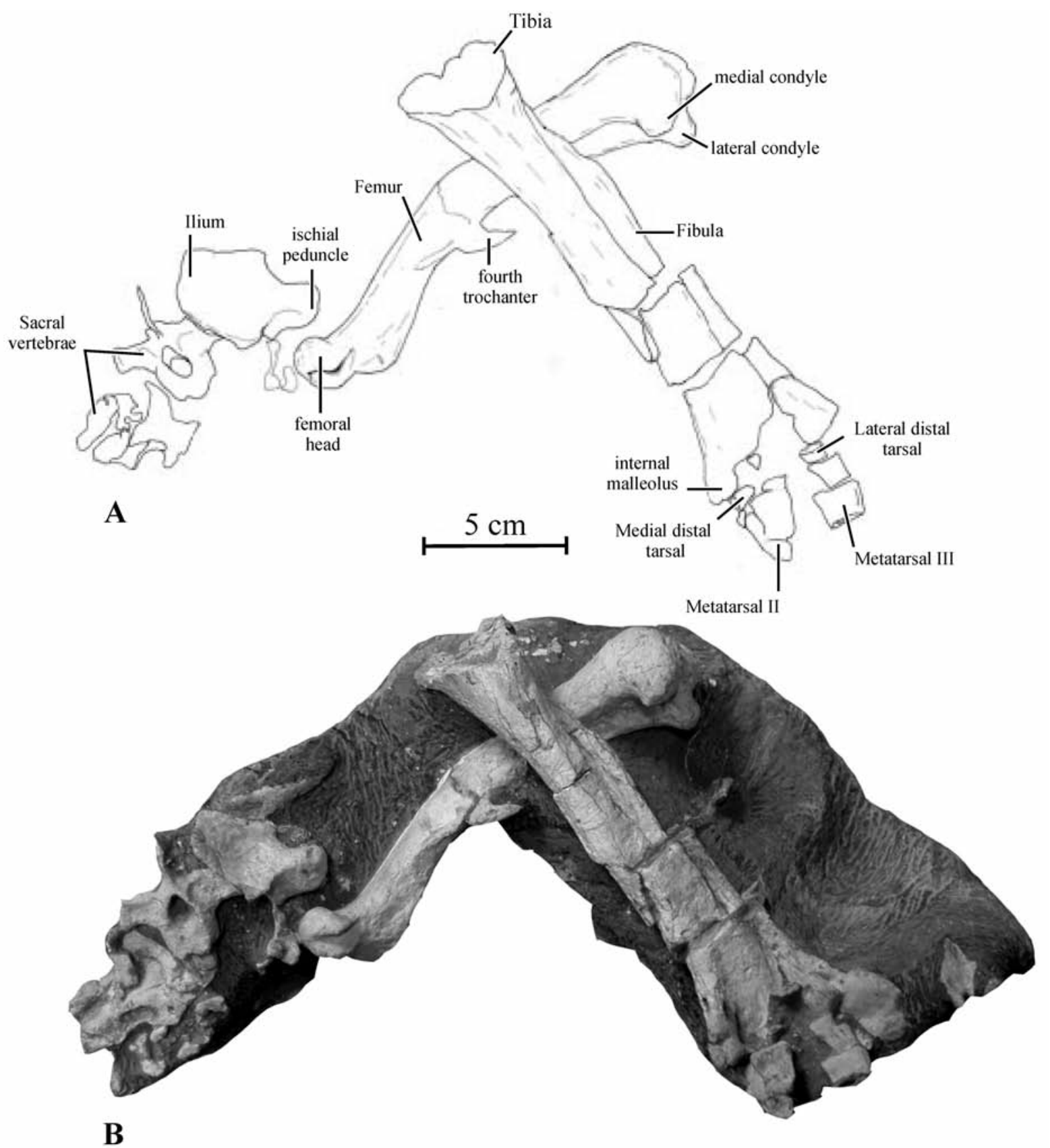

Fig. 14. Interpretative drawing (A) and photograph (B) of the paratype of Koreanosaurus boseongensis nov. gen., nov. sp. (KDRC-BB3).

'width of the sternal plate/length of the humerus' is between 0.23 and 0.24 in Koreanosaurus boseongensis. It is 0.34 in Hypsilophodon foxii (GALTON 1974, fig. 37), indicating that the humerus is proportionally larger in the Korean ornithopod.
$\mathrm{Hu}$ m e r u s . - The large size and massive aspect of the humerus is one of the most striking characters that can be observed in Koreanosaurus boseongensis. Only the proximal part of the right humerus is preserved in the holotype KDRC-BB2; the left humerus is nearly complete, but the humeral shaft is 

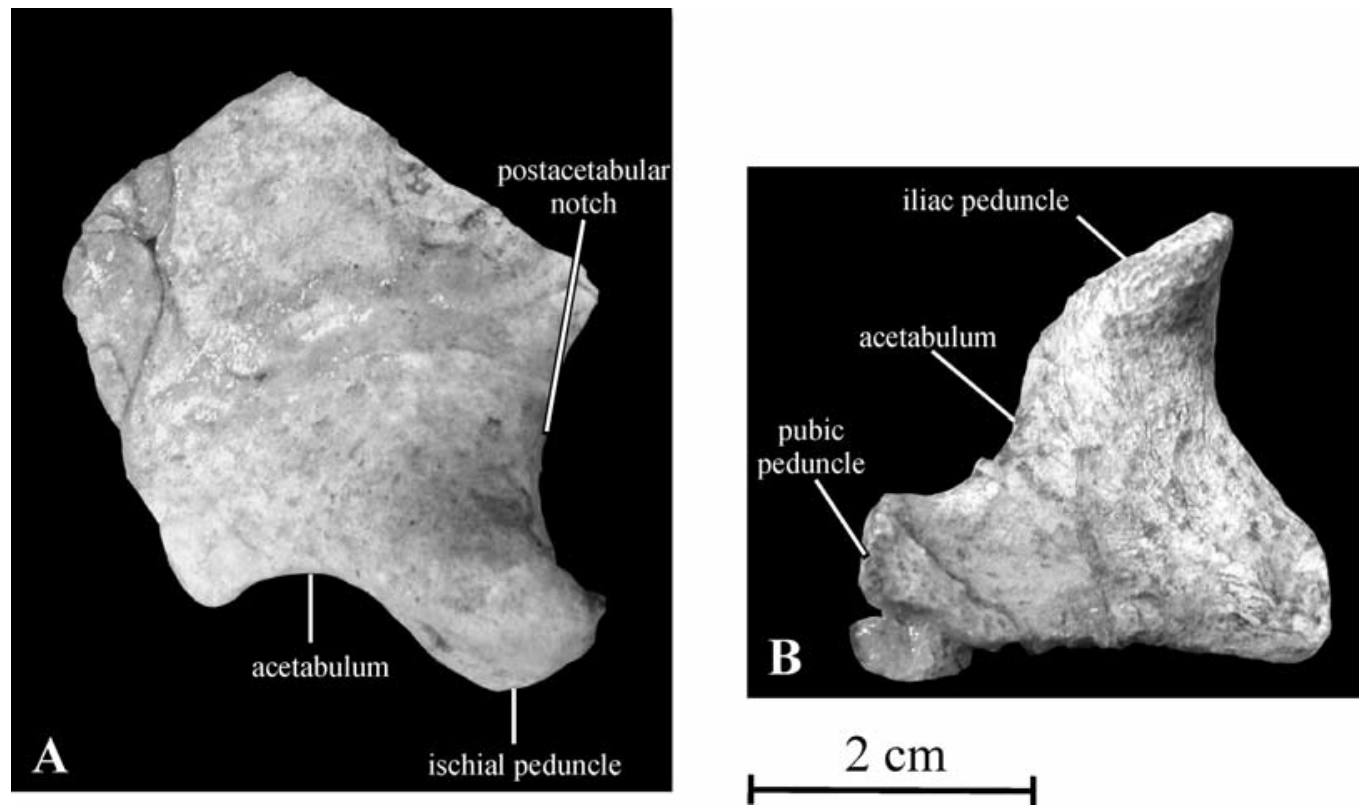

Fig. 15. Koreanosaurus boseongensis nov. gen., nov. sp. (KDRC-BB3). Middle part of the left ilium (A) and proximal part of the left ischium (B).

slightly damaged (Fig. 12). The minimal length of the left humerus is $205 \mathrm{~mm}$ (simple addition of the two separate parts) and the actual length of the bone can be estimated between 205 and $215 \mathrm{~mm}$. It is similar to the size of the left scapula $(205 \mathrm{~mm})$, but it is slightly longer than the adult femora KDRC-BB1 and BB3 (respectively 193.5 and $196.5 \mathrm{~mm}$; Table 2). The deltopectoral crest is better developed than in Hypsilophodon (see GALTON 1974: figs. 38-39), Orodromeus (SCHEETZ 1999, fig. 21), Oryctodromeus (VARRICCHIO et al. 2007, fig. 4d-e), and Jeholosaurus (PMOL LPM-R00104). It is only slightly turned anteriorly, less than in Hypsilophodon and Orodromeus; its base reaches the mid-length of the bone. The ventrolateral corner of the crest thickens and forms a broad, rugose surface for insertion of $m$. pectoralis medially and $m$. deltoides clavicularis laterally. On the anterior side of the humerus, the deltopectoral crest limits a shallow, but wide bicipital sulcus. The proximal articular head forms a rounded buttress in the middle of the posterior side of the humerus. Although it is eroded, it was apparently rather poorly developed. Both the medial and lateral tuberosities are poorly developed on the proximal border of the humerus; the articular head therefore looks supported by low shoulders in posterior view. The humeral shaft is robust and elliptical in cross-section. The distal portion of the humerus is slightly twisted medially and, although it is incompletely preserved, it appears more expanded mediolaterally than in Hypsilophodon (see GALTON 1974, figs. 38-39), Orodromeus (ScHEETz 1999, fig. 21), and Oryctodromeus (VARRICCHIO et al. 2007, fig. $4 \mathrm{~d}-\mathrm{e})$. The ulnar condyle is larger and extends more distally than the radial condyle. The olecranon fossa forms a shallow triangular depressed area on the posterior surface of the humerus.

Ulna and radius. - The proximal parts of the left ulna and radius are preserved in articulation with the distal part of the left humerus (Fig. 13). Although it is eroded, the olecranon process of the ulna appears moderately developed as is usual in basal ornithopods. In proximal view, the ulna is triangular in cross-section, with a regularly convex lateral border, a concave medial border and a slightly concave anterior articular border for radius. The posterior border of the ulna forms a sharp keel, as also observed in Orodromeus (SCHEETZ 1999, fig. 22 ). The posterior border of the ulna is usually gently rounded in hypsilophodontid-grade ornithopods, as observed for example in Hypsilophodon (GALTON 1974, fig. 40), Jeholosaurus (PMOL LPM-R00104), and Oryctodromeus (D. VARRICCHIO, pers.comm., April 2009). The anteromedial coronoid process forms a low and rounded crest that progressively 

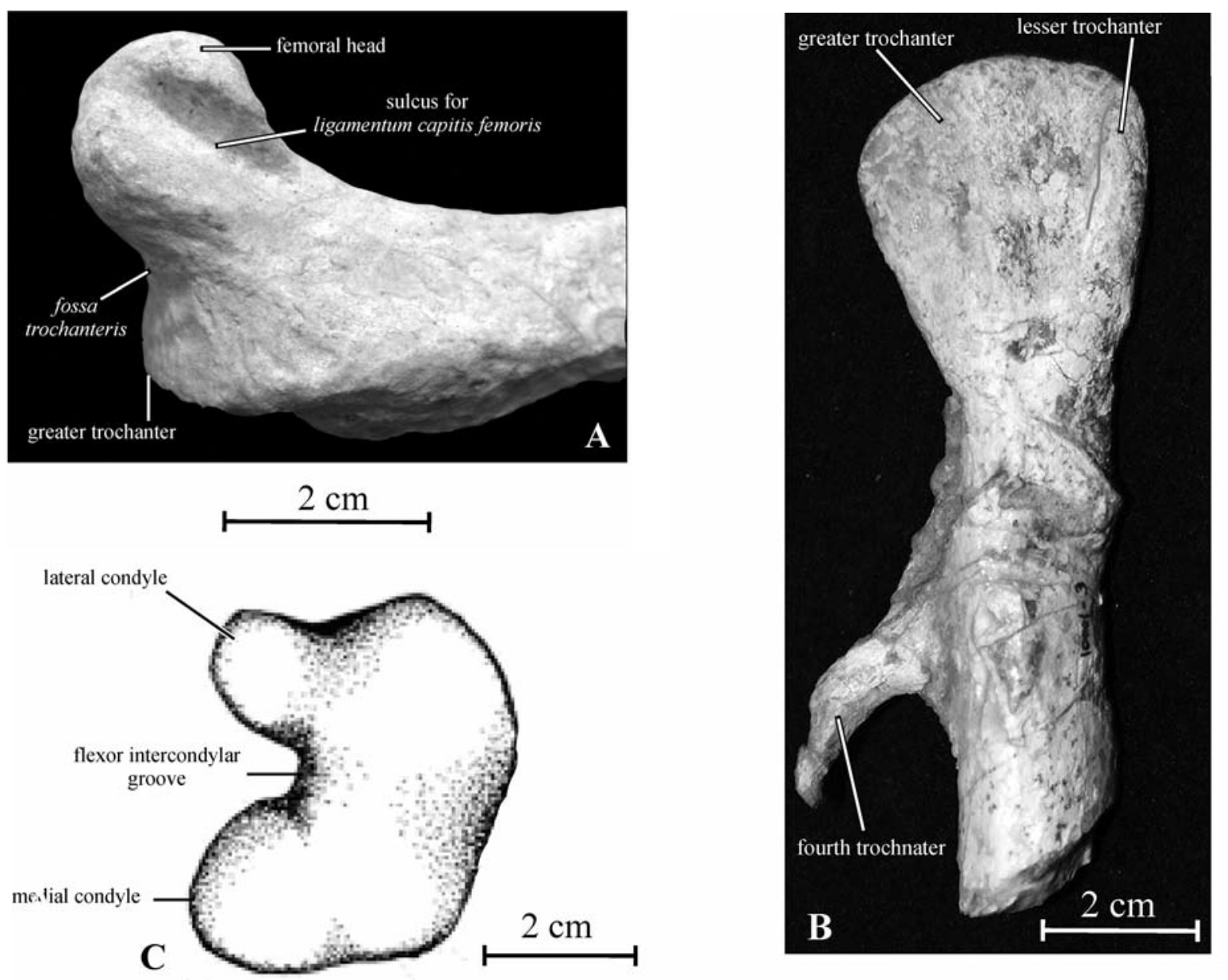

Fig. 16. Koreanosaurus boseongensis nov. gen., nov. sp. Proximal part of the left femur (KDRC-BB3) in posterior view (A). Proximal half of the right femur (KDRC-BB1) in lateral view (B). Interpretative drawing of the distal surface of the right femur (KDRC-BB1, C).

merges with the ulnar shaft. The anterolateral coronoid process is not developed at all. The articular facet for the proximal part of the radius is triangular in shape and smoothly concave. The ulna progressively tapers distally.

The shaft of the radius is more cylindrical and its proximal end is only slightly expanded.

I 1 i u m . - Only a small portion of the middle part of the left ilium is preserved in KDRC-BB3, connected with the ?fourth sacral vertebra and rib and in the vicinity of the left femur (Figs. 14-15A). Its dorsal edge is particularly sharp, as also observed in Hypsilophodon (GALTON 1974), Orodromeus (SCHEETz 1999), Jeholosaurus (PMOL LPM-R00104), and Changchunsaurus (JLUM L0403-j-Zn2). Its lateral side is perfectly flat above the acetabulum.
The acetabulum appears to have been fully perforate, lacking any kind of medial flange similar to that seen in basal ornithischians (BUTLER et al. 2008). Contrary to Stombergia and Agilisaurus (BUTLER et al. 2008), there is no trace of a vertical brevis shelf in Koreanosaurus. The ischial peduncle is particularly robust, projects strongly ventrolaterally and has a convex outline anteriorly in lateral view. The postacetabular notch appears much more obtuse than in Hypsilophodon (GALTON 1974, fig. 48), Orodromeus (SCHEETZ 1999, fig. 24), and Changchunsaurus (JLUM L0403-j-Zn2).

I s c h i u m . - The proximal head of the left ischium is associated with the paratype KDRC-BB3 (Fig. $15 \mathrm{~B})$. The pubic peduncle is partially preserved. It is subrectangular in lateral view and its ventral margin 
is compressed mediolaterally. Consequently, its concave articular surface is subtriangular in outline. The iliac peduncle is much better developed and projects strongly dorsolaterally. Its articular surface is smoothly concave and very rugose. The deep embayment between the iliac and pubic peduncles forms the posteroventral margin of the acetabulum.

Fe m u r. - The left femur is nicely preserved in the paratype KDRC-BB3 (Fig. 14). A nearly complete right femur KDRC-BB1 was discovered in site 3 and closely resembles the paratype in size and shape. The femur of Koreanosaurus appears proportionally small and rather lightly built. As is usual in basal ornithischians and ornithopods, it is regularly bowed anteriorly. The femoral head is particularly prominent and supported by a long neck (Fig. 16A). The femoral head and shaft form a $135^{\circ}$ angle and the head is consequently set more proximally than the trochanters. Usually in basal ornithopods, the angle between the femoral head and shaft is less than $110^{\circ}$ and the top of the head is set at bit above the greater trochanter, as e.g. observed in Hypsilophodon (GALTON 1974: fig. 54), Orodromeus (SCHEETZ 1999, fig.28), Jeholosaurus (PMOL LPM-R00104), and Changchunsaurus (JLUM L0403-j-Zn2). In medial view, the femoral head has a pyriform outline and its anteroposterior axis is larger than its proximodistal axis. In other basal ornithopods, the femoral head is usually compressed anteroposteriorly, as observed in Hypsilophodon (GALTON 1974, fig. 54), Orodromeus (ScheETZ 1999, fig. 28), Jeholosaurus (PMOL LPM-R00104), and Changchunsaurus (JLUM L0403-j-Zn2). The posterior surface of the femoral head is marked by a deep oblique sulcus for ligamentum capitis femoris; medial and lateral to the ligament sulcus the head is extended into posteriorly-directed lips. A similar morphology is present in Hypsilophodon (GALTON 1974, fig. 54), Orodromeus (ScheETz 1999, fig. 28), Jeholosaurus (IVPP V15939), and Changchunsaurus (JLUM L0403-j-Zn2), but the lateral lip is usually less developed in these taxa. The femoral head is separated from the trochanters on the proximal surface by a relatively deep and anteroposteriorly-extending fossa trochanteris. This fossa, absent in basal ornithischians, is generally present in cerapodans (BUTLER et al. 2008). Most of the lateral surface of the femur is formed by the greater trochanter, which has a convex dorsal margin in lateral view (Fig. 16B). The lateral surface of the

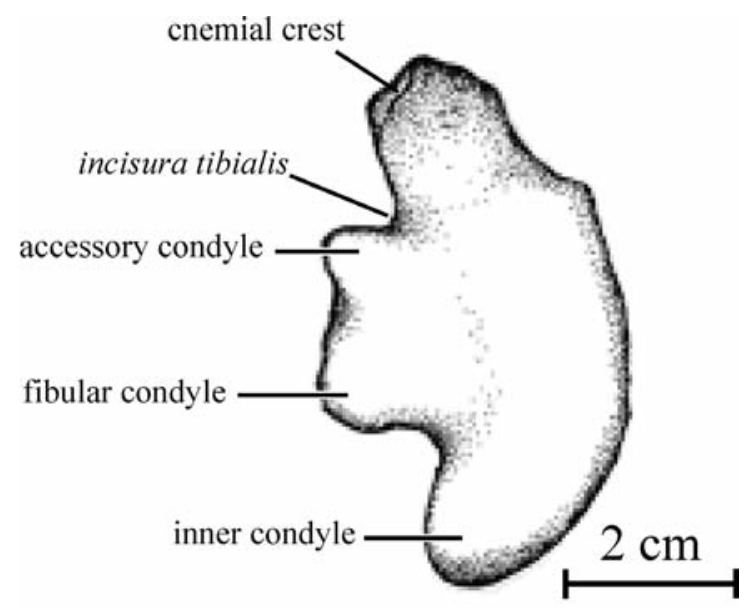

Fig. 17. Interpretative drawing of the proximal surface of the left tibia of Koreanosaurus boseongensis nov. gen., nov. sp. (KDRC-BB3).

greater trochanter is extensively depressed, delimited anteriorly by the lesser trochanter, and posteriorly by a prominent proximodistally extending ridge. A similar ridge has already been described on the lateral surface of the femur in Hypsilophodon (GAlton 1974), Jeholosaurus (IVPPV12529), Changchunsaurus (JLUM L0403-j-Zn2), Micropachycephalosaurus (BUTLER \& ZHAO 2009), Othnielosaurus (GALTON \& JENSEN 1973, fig. 5A), and has been identified as separating the insertions of the $M$. pubo-ischiofemoralis internus I (anteriorly) and the M. ilio-trochantericus (posteriorly) (GALTON 1969, 1974). The much smaller lesser trochanter is positioned anterior and slightly lateral to the greater trochanter; its proximal end forms a small pointing spike that nearly reaches the level of the dorsal margin of the greater trochanter. A vertical cleft separates the trochanters. Distal to the proximal end, the femoral shaft has a subtriangular cross-section. The fourth trochanter is located just above the midshaft. It is particularly prominent but slender, and has a hook-like pendent aspect in medial view. The medial condyle is stouter and extends further distally than the lateral condyle (Fig. 16C). The posterolateral surface of the lateral condyle forms a long but shallow vertical groove for $m$. iliofibularis. The flexor intercondylar groove is wide, deep, and fully open. Two ridges run obliquely from the distal condyles along the posterior surface of the shaft, limiting a large triangular propliteal region. The extensor intercondylar groove is not developed at all 


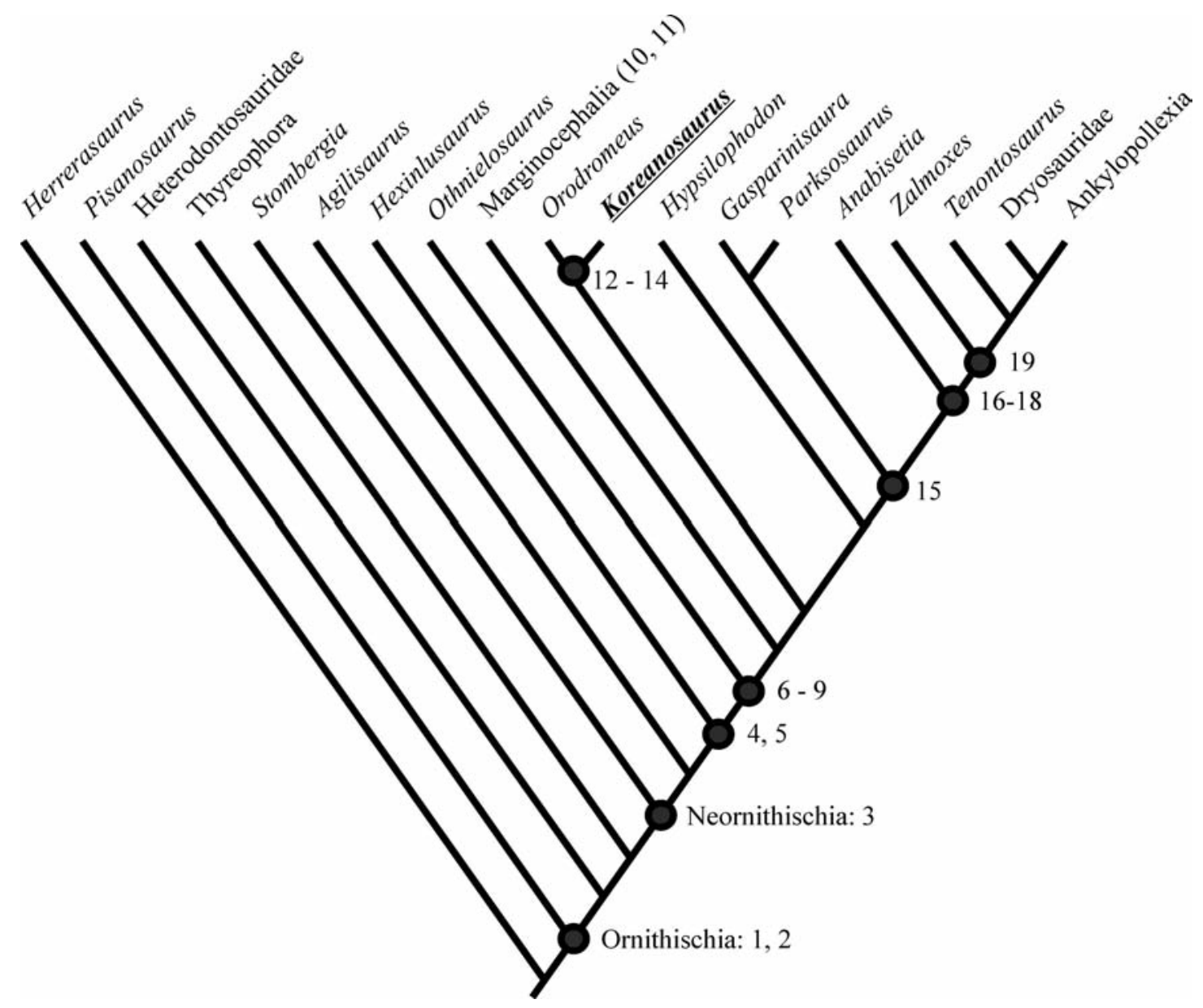

Fig. 18. Presumed position of Koreanosaurus boseongensis within ornithischian phylogeny (slightly modified from BuTLER et al. 2008, fig. 3). The numbers refer to characters whose polarity can directly be checked on the Koreanosaurus material at hand. 1: well-developed lesser trochanter on femur. 2: transverse expansion of distal tibia. 3: absence of epipophyses on cervicals. 4: absence of supra-acetabular flange on ilium. 5: absence of sub-vertical brevis shelf. 6: absence of vertical flange partially backing the acetabulum. 7: broadly swollen, ventrolaterally-projeting ischial peduncle on ilium. 8: fossa trochanteris separating femoral head and greater tochanter. 9: reduced lesser trochanter on femur. 10: scapular blade elongate and strap-like. 11: tongue-and-groove articulation between zygapophyses of dorsal vertebrae. 12: spine-like scapula acromion. 13: blade-like keel on centrum of all the cervical vertebrae. 14: highly-keeled proximal ulna. 15: fourth trochanter at or distal to femur mid-length. 16: postaxial cervicals opistocoelous. 17: extensor intercondylar groove developed on distal femur. 18: lateral condyle of distal femur reduced and medially inset. 19: flexor intercondylar groove partially closed on distal femur.

on the anterior side of the distal end of the femur, as also observed in basal ornithopods Hypsilophodon (GALTON 1974, fig. 54) and Orodromeus (SCHEETZ 1999, fig. 28). In Jeholosaurus (PMOL LPM-R00104) and Changchunsaurus, the extensor groove forms a shallow depression on the anterior side of the distal femur. This groove is much better developed in Anabisetia (Coria \& CAlvo 2002, fig. 7), Zalmoxes (Weishampel et al. 2003, fig. 23), and in more derived ornithopods (BUTLER et al. 2008).
Tibia . - The left tibia is preserved in the paratype KDRC-BB3, but its proximal head is partly destroyed and the sediment matrix obscures its posterior side (Fig. 14). The proximal part of a left tibia KDRC-BB1 was discovered in site 3. With an estimated length of $210 \mathrm{~mm}$, the paratype tibia is only slightly longer than the femur. The hindlimb ratio is 1.07 for tibia / femur, which is significantly lower than in other hypsilophodont-grade basal ornithopods: 1.17-1.19 in Hypsilophodon (GALTON 
1974, table 5), 1.18 in Parksosaurus (PARKs 1926), 1.19 in Oryctodromeus (VARRICCHIO et al. 2007) and in Jeholosaurus (IVPP V12529), and 1.25 in Orodromeus (MOR 294: Scheetz 1999). The hindimb ratio becomes lower than 1.10 only in more derived and larger ornithopods (GALTON 1974, table 5).

As is usual in basal ornithopods, the cnemial crest is poorly developed and projects anterolaterally (Fig. 17). A deep proximodistally-extending incisura tibialis separates the cnemial crest from the prominent fibular condyle. A smaller accessory condyle (see Thulborn 1972) is developed between the fibular condyle and the cnemial crest. The anteroventral border of the proximal fibula fitted against the depressed area between the fibular and accessory condyles. At the proximodorsal corner of the tibia, a hook-like inner condyle overhangs the fibular shaft. A broad notch separates the inner and fibular condyles from one another. The tibial shaft is long, slender, straight, and ovoid in cross-section. The lateral surface of the shaft is strongly convex, while the medial surface is slightly convex anteroposteriorly. The distal third of the tibia is mediolaterally expanded to form the distal malleoli and its anterior surface is flattened. The internal malleolus is very salient medially. The external malleolus is obscured by the sedimentary matrix and by the displaced distal portion of the fibula.

Fibula. - The left fibula is nearly completely preserved in the paratype KDRC-BB3 and is still in articulation with the tibia, but it is partly obscured by the sedimentary matrix (Fig. 14). This bone appears robustly built when compared with other basal ornithopods. Its proximal end is strongly expanded anteroposteriorly. The shaft narrows in anteroposterior width distally, but it remains anteroposteriorly expanded and transversely compressed along its proximal half. At this level, the lateral side is anteroposteriorly convex and the medial side is concave. At approximately midlength, the cross-section of the shaft progressively becomes transversely expanded. At its distal end the fibula is again expanded anteroposteriorly.

Tarsus and metatarsus. - The distal part of the hindlimb is poorly preserved in the paratype KDRC-BB3 because of faulting in the fossiliferous block, erosion and incomplete preparation of the specimen (Fig. 14). Therefore, it remains unclear whether the astragalus and the calcaneum are mis- sing or completely fused to the distal part of the tibia and the fibula. However, the rugose and regularly convex surface at the distal end of the 'tibia' closely resembles the ventral surfaces of an astragalus. The hypothetic fusion of the astragalus and calcaneum would indicate that this specimen belongs to an old adult individual. Two small disc-shaped flattened elements, located between the tibia, the fibula and the preserved metatarsals probably represent the distal tarsal elements. The proximal portions of metatarsal II and III are preserved in the paratype KDRC-BB3, but they are too damaged to be adequately described.

\section{Discussion}

\subsection{Affinities of Koreanosaurus boseongensis}

Recently, the phylogeny of basal ornithischians and ornithopods has been discussed in details in several papers (e.g. ScheETZ 1999; BuchHOLZ 2002; LiU 2004; Norman et al. 2004; Xu et al. 2006; ButLER et al. 2007, 2008). It is not the purpose of the present paper to propose new perspectives on the phylogeny of ornithischian dinosaurs, because the material that can be referred to as Koreanosaurus is too fragmentary and too many key-characters are not preserved.

On the basis of the available material, Koreanosaurus is tentatively positioned on BUTLER et al.'s (2008) phylogeny of Ornithischia, which is the most recent and detailed phylogenetic analysis of this major lineage of dinosaurs. Fig. 18 is a simplified version of BUTLER et al.'s (2008, fig. 3) maximum agreement subtree of 756 most parsimonious trees produced by analysing a data matrix of 46 taxa and 221 characters. Koreanosaurus was simply placed by hand on this cladogramme, on the base of the characters that can directly be observed on the Koreanosaurus material at hand.

The ornithischian nature of Koreanosaurus is confirmed by characters usually identified as ornithischian synapomorphies (e.g. SERENO 1986; Norman et al. 2004; ButLer et al. 2007, 2008), including a well-developed lesser trochanter on the femur (character 1; BUTLER et al. 2008, char. 199 (2)) and a strong transverse expansion of the distal end of the tibia (character 2; ButLer et al. 2008, char. 206). Within Ornithischia, Koreanosaurus displays a series of neornithischian synapomorphies, not present in basal ornithischians and thyreophorans: 
- The absence of epipophyses on the anterior postaxial cervicals (polarity unknown in Stombergia; character 3; BUTLER et al. 2008, char. 133).

- The absence of a supra-acetabular flange on the ilium (retained in Stombergia and Agilisaurus, but absent in all other neornithischians; character 4; ButLER et al. 2008, char. 176).

- The absence of a nearly vertical brevis shelf (retained in Stombergia and Agilisaurus; the brevis shelf is either horizontal or absent in all other neornithischians; character 5; BUTLER et al. 2008, char. 173).

- The absence of a vertical flange partially backing the acetabulum (retained in Stombergia, Agilisaurus, and Hexinlusaurus, but absent in all other neornithischians; character 6; BUTLER et al. 2008, char. 175).

- A broadly swollen ischial peduncle of the ilium that projects ventrolaterally (amongst basal neornithischians, the ischial peduncle projects ventrally in Stombergia, Agilisaurus, and Hexinlusaurus, only; character 7; BUTLER et al. 2008, char. 177).

- A fossa trochanteris modified into distinct constriction separating femoral head and greater trochanter (amongst basal neornithischians, the fossa trochanteris remains groove-like and the femoral head and greater trochanter are consequently confluent in Stombergia, Agilisaurus, and Hexinlusaurus, only; character 8; BUTLER et al. 2008, char. 198).

- A lesser trochanter with reduced anteroposterior width and closely appressed to the expanded greater trochanter (amongst basal neornithischians, the lesser trochanter is subequal in anteroposterior width to the greater trochanter and a deep notch is visible between them in Stombergia, Agilisaurus, and Hexinlusaurus, only; character 9; BUTLER et al. 2008, char. 199(3)).

Amongst Neornithischians, Koreanosaurus clearly lacks marginocephalians synapomorphies and we feel that such a referral is very unlikely: the scapular blades is proportionally short and broad, length is 5 times the minimum width (versus at least 9 times the minimum width in Marginocephalia; character 10; ButLer et al. 2008, char. 150), the articulation between the zygapophyses of dorsal vertebrae is apparently flat (versus tongue-and-groove in most Marginocephalia; character 11; ButLER et al. 2008, char. 136). Moreover, the humerus of Koreanosaurus lacks pachycephalosaurian synapomorphies: the deltopectoral crest is well developed (versus rudimentary, at most a thickening on the anterolateral margin of the humerus in Pachycephalosauria; BUTLER et al. 2008, char. 154) and the humeral shaft remains relatively straight (versus strongly bowed laterally along length in Pachycephalosauria; ButLER et al. 2008, char. 155).

In the descriptive part of the present paper, the great resemblance of the Koreanosaurus postcranium with that of hysilophodont-grade basal ornithopods has been highlighted. However, because of the absence of skull material and of the greatest part of the pelvic girdle, no true ornithopod synapomorphy can be recognized in the Koreanosaurus material at hand. But among ornithopods, Koreanosaurus shares an important development of the scapular spine with three taxa discovered in the Cretaceous of Montana (character 12): Zephyrosaurus schaffi from the Lower Cretaceous Cloverly Formation (SuEs 1980), Orodromeus makelai from the Upper Cretaceous Two Medicine Formation (Horner \& Weishampel 1988; ScheEtz 1999), and Oryctodromeus cubicularis from the mid-Cretaceous Blackleaf Formation (VARRICCHIO et al. 2007). Recent phylogenetic analyses show that these three Montana hypsilophodonts form a well-supported monophyletic group of very basal ornithopods (SCHEETz 1999; VARRICCHIO et al. 2007). Koreanosaurus shares additional features with at least one of these forms from Montana: the centra of the cervical vertebrae bear a blade-like keel (also observed in Orodromeus and Oryctodromeus; Varricchio, pers. comm., October 2009; character 13), the scapula and coracoid are completely fused together and form an enlarged scapulocoracoid (also observed in Oryctodromeus; VARRICCHIO et al. 2007, fig. 4c), the posterior border of the proximal ulna is highly keeled (also observed in Orodromeus; character 14). If Koreaosaurus can reasonably be identified as an ornithopod, then it displays a series of plesiomorphic features suggesting that, in any case, it occupied a basal position within this lineage, like the Montana ornithopod clade and Hypsilophodon itself:

- The fourth trochanter is entirely located on the proximal half of the femur, although it is positioned at midlength, or distal to midlength in Parksosaurus, Thescelosaurus, Zalmoxes, Tenodontosaurus, and Ankylopollexia (character 15; ButLer et al. 2008, char. 202). 
- The postaxial cervicals are amphicoelous, although they are at least slightly opistocoelous in Zalmoxes, Tenontosaurus, Dryosauridae and Ankylopollexia (polarity unknown in Anabisetia; character 16; BUTLER et al. 2008, char. 134).

- The extensor intercondylar groove is absent on the distal end of the femur, as in basal ornithischians and ornithopods. It is faintly developed in Jeholosaurus and Changchunsaurus (pers. obs.) and better developed in more advanced ornithopods such as Anabisetia, Zalmoxes, Tenontsaurus, Dryosauridae, and Ankylopollexia (character 17; BUTLER et al. 2008, char. 203).

- The lateral condyle of the distal femur is positioned relatively laterally and slightly narrower in width than the medial condyle. On the other hand, the lateral condyle is strongly inset medially and much reduced in width relative to the medial condyle in more advanced ornithopods such as Anabisetia, Zalmoxes, Tenontosaurus, Dryosauridae, and Ankylopollexia (character 18; BUTLER et al. 2008, char. 205).

- The flexor intercondylar groove of the femur is fully open. The medial condyle is inflated laterally and partly or completely covers the flexor groove in Zalmoxes, Tenontosaurus, Dryosauridae and Ankylopollexia (character 19; BUTLER et al. 2008, char. 204).

Without the discovery of additional material, it is clear that Koreanosaurus cannot be phylogenetically positioned with certainty. But with the fossils at hand, most features of the postcranial skeleton suggest affinities with basal ornithopods and, amongst them, particularly with a small clade formed by three genera from the Cretaceous of Montana: Zephyrosaurus, Orodromeus and Oryctodromeus. Only the discovery of more complete material, including skull elements, will allow this working hypothesis to be confirmed or refuted.

\subsection{Functional anatomy and palaeoecology}

On the basis of limb and trunk proportions and the generally gracile nature of their skeletons, basal ornithopods are usually regarded as strictly cursorial animals (GAlton 1974; CARrano 1999; Norman et al. 2004). The proportions of the postcranial skeleton of Koreanosaurus represent a marked departure from the typical cursorial hypsilophodontid body plan: the neck is elongated, both the scapula girdle and the forelimb are particularly elongated and massive, the hindlimb is proportionally short and the hindlimb ratio is low for tibia / femur. Even though it cannot be definitively proved that KDRC-BB2 and 3 do belong to the same individual, the size and robustness of the scapula and the humerus compared to the femur suggest that Koreanosaurus was a quadruped rather than a strictly cursorial biped like other hypsilophodontids. VARRICCHIO et al. (2007) convincingly demonstrated that the basal ornithopod Oryctodromeus was probably a burrowing dinosaur: skeletal remains of an adult and two juveniles were found in the expanded distal chamber of a sediment-filled burrow and this dinosaur exhibits features of the snout, shoulder girdle and pelvis consistent with digging habits, while retaining cursorial hindlimb proportions. Although associated burrows are currently unknown for Zephyrosaurus and Orodromeus, the skeletal features shared by all the three Montana hypsilophodonts, together with sedimentological and taphonomic data, suggest that the whole clade may have been specialized for digging (VARRICCHIO et al. 2007).

If Koreanosaurus is really closely related to the Montana hypsilophodont clade, a digging behaviour can therefore be hypothesized for the Korean ornithopod as well. The enlarged, fused scapulocoracoid with prominent acromion and scapular spine present in Koreanosaurus and Oryctodromeus would have increased attachment areas for muscles that were used to stabilize and operate digging forelimbs (Hildebrand 1985; VARricchio et al. 2007). The highly-keeled proximal ulna, described in Koreanosaurus and Orodromeus, is also clearly reminiscent of the high cubital crest observed in Talpidae and in the anteater Tamandua. This high crest provides large insertion areas to both extensor and flexor muscles for the carpus and the digits, in relation with the digging function of the hands in moles and anteaters (Lessertisseur \& SABAN 1967; HildeBRAND 1985; CASTIELLA et al. 1992).

The morphology of the hindlimb is certainly not in contradiction with a fossorial behaviour for Koreanosaurus. The femur, tibia and fibula appear proportionally short and the femoral head forms an obtuse angle of about $135^{\circ}$ with the shaft. It suggests that, if Koreanosaurus was quadruped, it could keep its thighs relatively outspread from the axis of the body, as observed in burrowing mammals such as the marsupial mole Notoryctes and, especially, Talpidae (Lessertisseur \& SABAN 1967). Such an orientation of the hindlimb allows firmer bracing of the back of 
the body when the animals dig with their forelimb (HiLDEBRAND 1985).

Like Oryctodromeus, Koreanosaurus lacks in any case the extreme skeletal modifications found in subterranean vertebrates, such as the mole (Talpa sp.), the golden mole (Amblysomus sp.), the wombat (Lasiorhinus sp.), the echidna (Tachyglossus aculeatus) and the aardvark (Orycteropus afer). Missing traits include the shortening of the neck and of the humerus, an elongate humeral head, a transverse expansion of the distal humerus, a prominent olecranon, and a compressed femoral head (HILDEBRAND 1985; VARRICCHIO et al. 2007).

From a taphonomical point of view, the preservation of well articulated and three-dimensional skeletons in palaeosol deposits, as it is the case for KDRC-BB2 and 3, is very unusual. It implies that the animal was buried very quickly just after its death or even that accidental burying was the cause of its death. Such a taphonomical situation is consistent with a burrowing behaviour for Koreanosaurus. The absence of bite marks and pre-fossilization breaks is inconsistent with carnivoregenerated bone assemblages (BRAIN 1981).

Burrows are particularly numerous just below sandstone beds in the Seonso Conglomerate. But most are very small, with a diameter of about $1 \mathrm{~cm}$ and lengths of a few $\mathrm{cm}$. They are filled with sandstone derived from the overlying sandstone layer (PAIK et al. 2006). We did not observe in the field much larger burrows that could have been dug by large animals such as Koreanosaurus. But uniformity of sediments around the fossiliferous pockets at site 5 may have obscured larger burrow preservation (VoORHIES 1975).

The sedimentological environment of Koreanosaurus and Oryctodromeus is also very similar. Both have been discovered in calcic and well-drained palaeosols, formed under semi-arid climatic conditions. Modern tetrapod burrowers prefer dryer soils (VoOrhies 1975; Groenewald et al. 2001; HAsiotis et al. 2004) and well-drained and seasonally-arid Cretaceous palaeosols, as observed in Montana and southern Korea, would represent favourable substrates for burrowers (VARRICCHIO et al. 2007).

Of course, because the skeleton of Koreanosaurus is still very incompletely known, it is highly speculative to interpret the very peculiar morphology of this dinosaur in terms of adaptation to a digging, burrowing behaviour. If such interpretation is reasonable, according to morphological, phylogenetic, sedimentological, and taphonomic data at hand, it must be confirmed by the discovery of much more complete material.

\section{Acknowledgements}

The authors are grateful to J. R. HoRnER (MOR), JIN L.-Y., Chen J. (JLUM), Sun Ge (PMOL), and Dong Z.-M. (IVPP), for access to the collections in their care, to R. J. Butler, P. M. Galton, and D. J. Varricchio for helpful discussions and information. Especially we deeply thank D. B. NoRMAN for supporting travel to Cambridge University, and I. S. PAIK for constructive criticisms and supports of field work. This research was funded by a grant from the Korean Science and Engineering Foundation (KOSEF-R01-2008-000-20056-0) and partly supported by Korea Research Foundation Grant KRFBK21. P. M. GALTON and D. J. VARRICCHIO kindly reviewed a first draft of this paper and made many helpful comments.

\section{References}

BrAIN, C. K. (1981): The hunters or the hunted? An introduction to African cave taphonomy. - 296 pp.; Chicago (University of Chicago Press).

BuchHolz, P. W. (2002): Phylogeny and biogeography of basal Ornithischia - In: BRown, D. E. (Ed.): The Mesozoic in Wyoming, 18-34; Casper (Tate Geological Museum, Casper College).

Butler, R. J. \& Galton, P. M. (2008): The 'dermal armour' of the Wealden dinosaur Hypsilophodon: a reappraisal. - Cretaceous Research, 29: 636-642.

Butler, R. J., SMith, R. M. H. \& Norman, D. B. (2007): A primitive ornithischian dinosaur from the Late Triassic of South Africa, and the early evolution and diversification of Ornithischia. - Proceedings of the Royal Society, (B), 274: 2041-2046.

Butler, R. J., Upchurch, P. \& Norman, D. B. (2008): The phylogeny of the ornithischian dinosaurs. Journal of Systematic Palaeontology, 6: 1-40.

Butler, R. J. \& ZhaO, Q. (2009): The small-bodied ornithischian dinosaurs Micropachycephalosaurus hongtuyanensis and Wannanosaurus yansiensis from the Late Cretaceous of China. - Cretaceous Research, 30: 63-77.

Calvo, J. O., Porfiri, J. D. \& Novas F. E. (2007): Discovery of a new ornithopod dinosaur from the Portezuelo Formation (Upper Cretaceous), Neuquén, Patagonia, Argentina. - Arquivos do Museu Nacional, Rio de Janeiro, 65 (4): 471-483.

Carrano, M. T. (1999): What, if anything, is a cursor? Categories versus continua for determining locomotor habit in mammals and dinosaurs. - Journal of Zoology, London, 247: 29-42.

Castiella, M. J., Laville, E., Renous, S. \& Gasc, J.-P. (1992): Caractéristiques morphologiques du membre antérieur de la taupe commune, Talpa europaea (Mammalia, Talpidae). - Mammalia, 56 (2) : 265-285. 
Chough, S. K., Kwon, S. T., Lee, J. H. \& Choi, D. K. (2000): Tectonic and sedimentary evolution of the Korean peninsula: a review and new view. - EarthScience Reviews, 52: 175-235.

COOPER, M. R. (1985): A revision of the ornithischian dinosaur Kangnasaurus coetzeei HaUghton, with a classification of the Ornithischia. - Annals of the South African Museum, 95: 281-317.

Coria, R. A. \& Calvo, J. O. (2002): A new iguanodontian ornithopod from Neuquén Bain, Patagonia, Argentina. - Journal of Vertebrate Paleontology, 16: 445-457.

Galton, P. M. (1969): The pelvic musculature of the dinosaur Hypsilophodon (Reptilia: Ornithischia). Postilla, 131: 1-64.

- (1974): The ornithischian dinosaur Hypsilophodon from the Wealden of the Isle of Wight. - Bulletin of the British Museum (Natural History), Geology, 25: $1-152 \mathrm{c}$.

- (2006): Teeth of ornithischian dinosaurs (mostly Ornithopoda) from the Morrison Formation (Upper Jurassic) of Western USA - In: CARPENTER, K. (Ed.): Horns and beaks. Ceratopsians and ornithopods dinosaurs, 17-47; Bloomington (University of Indiana Press).

Galton, P. M. \& Jensen, J. A. (1973): Skeleton of a hypsilophodontid dinosaur (Nanosaurus (?) rex) from the Upper Jurassic of Utah. - Brigham Young University Geology Studies, 20: 137-157.

Gilmore, C. W. (1915): Osteology of Thescelosaurus, an orthopodous dinosaur from the Lance Formation of Wyoming. - Proceedings of the United States National Museum, 49: 591-616.

Groenewald, G. H., Welman, J. \& MacEachern, J. A. (2001): Vertebrate burrow complexes from the Early Triassic Cynognathus Zone (Driekoppen Formation, Beaufort Group) of the Karoo Basin, South Africa. Palaios, 16: 148-160.

Hasiotis, S. T., Wellner, R. W., Martin, A. J. \& Demko, T. M. (2004): Vertebrate burrows from Triassic and Jurassic continental deposits of North America and Antarctica: their paleoenvironmental and paleoecological significance. - Ichnos, 11: 103-124.

HE, X. \& CAI, K. (1984): The Middle Jurassic dinosaur fauna from Dashanpu, Zigong, Sichuan. Vol. 1, The ornithopod dinosaurs. - 71 pp.; Chengdu (Sichuan Scientific \& Technological Publishing House). [In Chinese with English summary].

Hildebrand, M. (1985): Digging in quadrupeds. - In: Hildebrand, M., Bramble, D. M., Liem, K. F. \& WAKE, D. B. (Eds.): Functional vertebrate morphology, 89-109; Cambridge, MA (Belknap Press).

Horner, J. R. \& Weishampel, D. B. (1988): A comparative embryological study of two ornithischian dinosaurs. - Nature, 332: 256-257.

Huh, M., Lim S., Yang, S.Y. \& Hwang, K. G. (1997): A preliminary report on Cretaceous dinosaur tracks from the Uhangri Formation, Korea. - Journal of the Paleontological Society of Korea, Special Publication, 2: 1-16.
Huh, M., Paik, I. S., Chung, C. H., Park, J. B. \& Kim, B. S. (2001): Dinosaur tracks from islands in Yeosu, Jeollanam-do, Korea. - Journal of the Geological Society of Korea, 37: 653-658.

Huh, M., Paik, I. S., Lee, Y. I. \& Kim, H. K. (1999): Dinosaur eggs and nests from Boseong, Chullanamdo. - Journal of the Geological Society of Korea, 35: 229-232.

Huh, M., Paik, I. S., Lee, Y. I \& Park, K. H. (2006): A research on the Boseong dinosaur eggsite, Korea. 229 pp.; Korea Dinosaur Research Center of Chonnam National University and Boseong-gun County. [In Korean].

Huh, M. \& Zelenitsky, D. K. (2002): Rich dinosaur nesting site from the Cretaceous of Bosung County, Chullanam-Do Province, South Korea. - Journal of Vertebrate Paleontology, 22 (3): 716-718.

Hwang, I. J., Cheong, C. S. (1968): Explanatory text of the geological map of Boseong sheet (1:50 000). 9 pp.; Seoul (Geological Survey of Korea).

Kang, P. C., Chwac, U. C., Kim, K. B., Hong, S. H., Lee, B. J., Hwang, J. H., Park, K. H., Hwang, S. K., Choi, P. Y., Song, K. Y. \& JIN, M. S. (1995): Geological Map of Korea $(1: 1,000,000)$. - Seoul (Korean Institute of Geology, Mining, and Materials).

KIM, C. B., KIM, J. M. \& HuH, M. (2008): Age and stratification of dinosaur eggs and cluches from Seonso Formation, South Korea. - The Journal of the Korean Earth Science Society, 29: 386-395.

LEE, D. W. (1999): Strike-slip fault tectonics and basin formation during the Cretaceous in the Korean Peninsula. - Island Arc, 8: 218- 231.

Lee, Y. N., Jeong, K. S., Chang, S. K., Choi, M. Y. \& Chor, J. I. (2000): The preliminary research on the dinosaur eggs and nests found in the reclaimed area south to the Siwha Lake, Gyeonggi Province, Korea.Journal of the Paleontological Society of Korea, 16: 27- 36.

LeE, Y. N., YANG, S. Y. \& PARK, E. L. (1997): Sauropod dinosaur remains from the Gyeongsang Supergroup, Korea. - Paleontological Society of Korea, Special Publication, 2: 103-114.

Lessertisseur, J. \& SABAN, R. (1967): Squelette appendiculaire - In: Grassé, P.-P. (Ed.): Traité de Zoologie, tome 16 (1): Mammifères - tégument - squelette, 707-1078; Paris (Masson).

Lim, S. K., Lockley, M. G., YANG, S. Y., Fleming, R. F. \& Houck, K. (1994): A preliminary report on sauropod tracksites from the Cretaceous of Korea. - Gaia, 10: $109-117$

LIU, J. (2004): Phylogeny of Ornithischia. - Journal of Vertebrate Paleontology, 24 (supplement): 84A.

Marsh, O. C. (1881): Classification of the Dinosauria. American Journal of Science, series 3, 23: 81-86.

Norman, D. B., Sues, H.-D., Witmer, L. M. \& Coria, R. A. (2004): Basal Ornithopoda - In: WeIshampel, D. B., Dodson, P. \& Osmólska, H. (Eds.): The Dinosauria (Second Edition), 393-412; Berkeley (University of California Press). 
Novas, F., Cambiaso, A. \& Ambrosio, A (2004): A new basal iguanodontian (Dinosauria, Ornithischia) from the Upper Cretaceous of Patagonia. - Ameghiniana, 41: $75-82$.

Owen, R. (1842): Report on British fossil reptiles, part II. - Report for the British Association for the Advancement of Science, Plymouth, 1841: 60-294.

Paik, I. S., Kim, H. J., PARK, K. H., Song, Y. S., LeE, Y. L., Hwang, J. Y. \& HuH, M. (2001): Palaeoenvironments and taphonomic preservation of dinosaur bone-bearing deposits in the Lower Cretaceous Hasandong Formation, Korea. - Cretaceous Research, 22: 627- 642.

PAIK, I. S., LeE, Y. I. \& KIM, H. J. (1998): Dinosaur beds of the Gyeongsang Supergroup: taphonomy and paleoenvironments. - Journal of the Geological Society of Korea, 34: 243-265.

PAIK, S., HuH, M. \& Kim, H.-J. (2004): Dinosaur eggbearing deposits (Upper Cretaceous) of Boseong, Korea: occurrence, palaeoenvironments, taphonomy, and preservation. - Palaeogeography, Palaeoclimatology, Palaeoecology, 205: 155-168.

PARKs, W. A. (1926): Thescelosaurus warreni, a new species of ornithopodous dinosaur from the Edmonton Formation of Alberta. - University of Toronto Studies (Geological Series), 21: 1-42.

ScHEETZ, R. D. (1999): Osteology of Orodromeus makelai and the phylogeny of basal ornithopod dinosaurs. Unpublished PhD thesis, 186 pp.; Bozeman (Montana State University).

SeEley, H. G. (1887): On the classification of the fossil animals commonly named Dinosauria. - Proceedings of the Royal Society of London, 43: 165-171.

Sereno, P. C. (1986): Phylogeny of the bird-hipped dinosaurs (Order Ornithischia). - National Geographic Research, 2: 234-256.

- (1998): A rationale for phylogenetic definitions, with application to the higher-level taxonomy of Dinosauria. - Neues Jahrbuch für Geologie und Paläontologie, Abhandlungen, 210: 41-83.

SuEs, H.-D. (1980): Anatomy and relationships of a new hypsilophodontid dinosaur from the Lower Cretaceous of North America. - Palaeontographica, (A), 169: 51-72.
Thulborn, R. A. (1972): The postcranial skeleton of the Triassic ornithischian dinosaur Fabrosaurus australis. - Palaeontology, 15: 29-60.

VArricchio, D. J., Martin, A. J. \& Katsura, Y. (2007): First trace and body fossil evidence of a burrowing, denning dinosaur. - Proceedings of the Royal Society, (B), 274: 1361-1368.

VoORhies, M. R. (1975): Vertebrate burrows - In: Frey, R. W. (Ed.): The study of trace fossils, 325-350; New York (Springer).

Weishampel, D. B., Jianu, C.-M., Csiki, Z. \& Norman, D. B. (2003): Osteology and phylogeny of Zalmoxes (N. G.), an unusual euornithopod dinosaur from the latest Cretaceous of Romania. - Journal of Systematic Palaeontology, 1: 65-123.

Xu, X., Forster, C. A. Clark, J. M. \& Mo, J.-Y. (2006): A basal ceratopsian with transitional features from the Late Jurassic of northwestern China. - Proceedings of the Royal Society of London, (B), 273: 2135-2140.

YANG, S. Y. (2000): Some findings from the Goseong-gun project. - $16^{\text {th }}$ Symposium of the Paleontological Society of Korea: 17.

Manuscript received: September 14th, 2009.

Revised version accepted by the Stuttgart editor:

November 16th, 2009.

\section{Addresses of the authors:}

Min Huh, Dae-Gil Lee, Jung-Kyun Kim, Faculty of Earth Systems and Environmental Sciences \& Korea Dinosaur Research Center, Chonnam National University, Gwangju, 500-757, Republic of Korea;

e-mail:minhuh@chonnam.ac.kr

JoNG-DeOCK Lim, Natural Heritage Center of Cultural Heritage Administration, 396-1 Mannyeon-dong, Seo-gu, Daejeon, 302-834, Republic of Korea

PASCAL GodeFroIT (corresponding author), Royal Belgian Institute of Natural Sciences, Department of Palaeontology, rue Vautier 20, 1000 Brussels, Belgium;

e-mail: Pascal.Godefroit@nauralsciences.be 